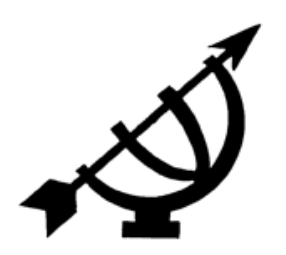

\title{
Luther als protestantischer Katechet
}

\author{
U. Kern $\mathbf{1}$ \\ Guest lecturer: Department of Ecclesiology \\ University of the Free State \\ BLOEMFONTEIN \\ E-mail: udo.kern@uni-rostock.de
}

\begin{abstract}
Luther as protestant catechist

Luther's catechetical activity is based on the catechetic tradition already extant in the Early Church. He reverts to this tradition, and more especially to the catechetical instruction of the Middle Ages. Luther observed great negligence and deficiency with regard to the catechesis in the Roman Catholicism of his time. In Luther's view, a catechism is a short summary of Holy Scripture; it is a condensed and succinct expression of the teachings of the Christian faith. Along with his study on the unfree will ("De servo arbitrio") Luther considered his two catechisms, which developed out of his preaching activity, as his most important written work. His "Small catechism", which was very well received, was reissued more than 60 times - and translated into a variety of languages - up until the time of his death.
\end{abstract}

According to Luther, catechesis (catechetical instruction) is the means by which the catechism is to be learned. A vital part of this process is that the catechism must take root in the heart. The catechism is not a vehicle for objective, scientific faith, but rather defines a living, personal faith as trust in God. All Christians, including adults, must therefore know the catechism in such a way that it is engraved on their consciousness. This necessitates the attendance of catechetical sermons. There is much pneumatological profit to be had in the reading and discussion of the catechism, and in meditating on it, because the Holy Spirit is present in all these activities. All that is necessary for the Christian to know about his salvation is richly

1 Prof. Dr. em. Udo Kern, emeritierter Professor für Systematische Theologie, Universität Rostock, Deutschland, udo.kern@uni-rostock.de 
and thoroughly present in the catechism. In the light of this, the catechism is profoundly trinitarian and eschatological in orientation. The catechism teaches that the fulfilment of the Ten Commandments, the realisation of the good, is born out of true faith. Those who do not know the catechism are not allowed to partake in the sacrament of the Lord's Supper.

\section{Opsomming}

\section{Luther as protestantse kategeet}

Luther se kategetiese werksaamheid is gebaseer op die kategetiese tradisie wat reeds sedert die Vroeë Kerk bestaan het. Hy val daarop terug en veral op die middeleeuse kategismusonderrig. In die Roomse katolisisme van sy tyd het Luther groot gebreke en nalatigheid ten opsigte van kategismusonderrig waargeneem. Vir Luther is die kategismus 'n kort samevatting van die Heilige Skrif. Op 'n beknopte wyse word Christelike leer hierin tot uitdrukking gebring. Naas sy studie oor die onvrye wil ("De servo arbitrio") het Luther sy twee kategismusse, wat uit preekwerksaamhede gegroei het, as die belangrikste van sy geskrifte geag. Sy "Klein kategismus" wat geweldige aanklank gevind het, is tot en met sy dood meer as 60 keer opnuut heruitgegee en ook in verskeie ander tale vertaal.

Volgens Luther is kategismusonderrig toerusting ("instructio") wat daarop gemik is, dat die kategismus geleer moet word. Deurslaggewend daarvoor is dat dit in die hart moet wortel skiet. Die kategismus dra nie wetenskaplike geloof oor nie, maar sit die lewende persoonlike geloof uiteen as vertroue in God. Alle Christene, ook volwassenes, moet die kategismus ken en dit in hulle bewussyn inprent. Om die kategismuspreke by te woon, is noodsaaklik. By die lees, praat en denke oor die kategismus is die Heilige Gees teenwoordig. Dit bring dus pneumatologiese gewin. Alles wat vir 'n Christen noodsaaklik is om vir sy heil te weet, is deeglik en baie volledig in die kategismus saamgevat. Die kategismus is as sodanig trinitaries en eskatologies gerig. Uit ware geloof volg die nakoming van die Tien Gebooie, die nakoming van die goeie - so leer die kategismus. Wie die kategismus nie ken nie, word nie tot gebruik van die sakramente toegelaat nie.

\section{Zusammenfassung}

\section{Luther als protestantischer Katechet}

Luthers katechetischen Bemühungen ruhen auf den katechetischen Traditionen seit der alten Kirche. Er knüpft an diese und insbesondere an den mittelalterlichen Katechismusunterricht an. Im zeitgenössischen römischen Katholizismus diagnostiziert Luther schwere Defizite und Vernachlässigungen 
hinsichtlich des Katechismusunterrichtes. Der Katechismus ist für Luther kurze Zusammenfassung der Heiligen Schrift. Komprimiert wird hier ausgesagt, was christliche Lehre ist. Von seinen Schriften achtete Luther die beiden Katechismen neben seiner Abhandlung zum Unfreien Willen („De servo arbitrio“) am meisten. Seine Katechismen erwachsen Luther aus seiner diesbezüglichen Predigttätigkeit. Sehr verbreitet war Luthers „Kleiner Katechismus“, der bis zu seinem Tod über 60 Ausgaben hatte und in verschiedene andere Sprachen übersetzt wurde.

Der Katechismusunterricht ist ein Unterricht (,instructio“), der darauf aus ist, dass der Katechismus gelernt werden muss. Entscheidend ist, dass er im Herzen verwurzelt wird. Der Katechismus vermittelt nicht "wissenschaftlichen Glauben“, sondern gibt Kunde von dem lebendigen, den Einzelnen treffenden Glauben als Vertrauen auf Gott. Alle Christen, auch Erwachsene, müssen den Katechismus kennen und sich einprägen. Notwendig ist der Besuch der Katechismuspredigten. Beim Lesen, Reden und Gedenken des Katechismus ist der Heilige Geist gegenwärtig, stellt sich also pneumatologischer Ertrag ein. Alles, was dem Christen zum Heil notwendig ist zu wissen, ist gründlich und reichlich im Katechismus zu finden. Als solcher ist der Katechismus trinitarisch und eschatologisch grundorientiert. Aus authentischem Glauben - so lehrt der Katechismus - folgt das Tun der Zehn Gebote, das Tun des Guten. Wer den Katechismus nicht kennt, ist nicht zum Sakrament zugelassen.

\section{Einleitung}

"Der Name Katechismus“, heißt es in einer von Gustav Kawerau 1890 herausgegebenen Schrift, „dient einerseits zur Bezeichnung eines ganz bestimmten Stoffes, dessen fester Grundstock seit dem Ende des Mittelalters die drei Stücke Dekalog, Symbolum apostolicum und Vaterunser bilden, andererseits weist der Name auf die Darbietung dieses Stoffes an die Anfänger im Christentum und zwar mit der Abzweckung auf mündlichen Unterricht."2 Mit dieser Definition ist Wichtiges und Elementares ausgesagt. Sie kann unterstützt und präzisiert werden durch die von Hans-Jürgen Fraas: „Mit ,Katechismus' wird in der christlichen Tradition einmal der Vorgang des Taufunterrichts, dann der Stoff desselben und schließlich

2 Kawerau (1890:5). 
das den Stoff enthaltende Buch bezeichnet."3 Wenn Luther 4 selbst vom Katechismus spricht, so meint er damit den Dekalog, das Credo und das Vaterunser. 5 „Der christliche Glaube ,ist' sein Inhalt, zusammengefasst im Katechismus" und als solcher „erheischt er Hingabe“, ja unbedingte Verbindlichkeit für Luther. 6

\section{Katechumenenunterricht - Katechismustraditionen}

Matthäus 28,19f. zeigt, dass die christliche Gemeinde von Anfang an christologisch fundiert Unterweisung intendierte und ausübte. Das (lehrmäßige) Bekanntmachen mit dem christlichen Glauben dokumentiert der altkirchliche Katechumenenunterricht. Dieses geschah im Zusammenhang eines prae- oder postbaptistalen Taufunterrichtes. Grundelemente des altkirchlichen Katechumenenunterrichts waren das Vaterunser, das Doppelgebot der Gottes- und Nächstenliebe sowie natürlich ein Taufbekenntnis.

Im Neuen Testament hat das griechische Wort katecho, in dem die Begriffe Katechismus und catechizare ethymologisch wurzeln, die Bedeutungen festhalten und zurückhalten. Es wird in übertragenem Sinn positiv und negativ verwandt: „1) Negativ: von ,den Menschen, die die Wahrheit in Ungerechtigkeit niederhalten' (Röm. 1,18), von der Gesetzesmacht, ,in der wir (gefangen-)gehalten wurden' (Röm. $7,6[\ldots]) .2$ 2) Positiv in überwiegend paränetischer Richtung beim Festhalten ,des Wortes' (Luk. 8,15 [...]), ,der Überlieferungen' (1. Kor. 11,2), ,des Evangeliums' (1. Kor. 15,2) ,des Guten' (1. Thess. 5,21), der Zuversicht, Hoffnung, des Bekenntnisses (Hebr. 3,6.14 [Bedeutung unsicher]; 10,23)."7

Das Wort katecho wird Acta 18,25 in der Bedeutung jemanden unterweisen gebraucht. Bei den Apostolischen Vätern (vgl. 2. Clem.

$3 \quad$ Fraas (1977:710).

4 Luther wird zitiert nach: 1. Martin Luther, Werke. Kritische Gesamtausgabe, Weimar 1883ff. (mit den Siglen: WA [Schriften], WA BR [Briefwechsel], WA DB [Deutsche Bibel], WA TR [Tischreden]), AWA [Archiv zur Weimaraner Lutherausgabe], 2. Die Bekenntnisschriften der evangelisch-lutherischen Kirche, Berlin 1960 (zitiert: BSLK) und 3. Tischreden oder Colloquia Doct. Mart. Luthers, hg. Johannes Aurifaber, Eisleben 1566 (zit. Aurifaber, Tischreden).

5 Schwarzwäller (2000:22).

6 Schwarzwäller (2000:31).

$7 \quad$ Trilling (1992:670f.). 
17,1) firmiert katechein lehrmäßig technisch für den Taufunterricht. Mit dem Verb catechizare, von dem sich der Katechismusbegriff herleitet, wird bei Tertullian (Adv. Marc. IV,29) und Augustin (De fide et op. 6,13) der mündliche lehrmäßige Taufunterricht bezeichnet. Catechismus heißt im 4. Jahrhundert in Nordafrika der mündliche Taufunterricht. Augustins um 400 verfasstes Buch, das er als eine Einführung in das Christentum verstand, hat den Titel De catechizandis rudibus. In seiner Schrift De sacramento baptismi (C. 1, MPL 99, 856B) definiert Leidradus von Lyon (gestorben 813): "Catechizare est instruere (Katechisieren ist Unterrichten)“. 8

Luther ist einerseits geformt durch diese Katechismustradition, wenn er schreibt: „Katechismus aber heißt ein Unterricht, damit man die Heiden, die Christen werden wollen, lehrt und weiset, was sie glauben, tun, lassen und wissen sollen im Christentum“ (WA 19, 76,2-5). Anderseits wird Luther durch die spätmittelalterliche Katechismusauffassung geprägt und hat deren Katechismuspraxis in der römisch-katholischen Kirche vor Augen. Luther würdigt die päpstliche Kirche für die rechte Überlieferung 1) der Heiligen Schrift und 2) der Hauptstücke des Katechismus. Er schreibt 1528: „Wir bekennen aber, dass unter dem Papsttum viel christliches Gutes, ja alles christliche Gut sei. Und daselbst herkommen sei an uns. Nämlich wir bekennen, dass im Papsttum die rechte Heilige Schrift sei, rechte Taufe, rechtes Sakrament des Altars, rechte Schlüssel zur Vergebung der Sünde, rechtes Predigtamt, rechter Katechismus, nämlich das Vaterunser, Zehn Gebote, die Artikel des Glaubens" (WA 26, 147,13-18). Luthers weitgehende Anknüpfung an die vorgefundene Tradition ist Ausdruck davon, dass Luthers Katechismen gemeinkirchlich orientiert sind und seinen „Willen zur Einheit und zur Ökumenizität der Kirche" 9 dokumentieren. Formal und inhaltlich hat sich Luther „in vielem an die Tradition des Mittelalters angeschlossen: er trennt beim Dekalog in der Zählung 9. und 10. Gebot und lässt das Bilderverbot aus, behält auch die Verkürzung des 1. und 2. Gebots und die Neufassung des 3. Gebots bei, die er vorfand, ebenso lässt er die Doxologie des Vaterunsers [...] aus." 10 Aus heutiger systematisch-theologischer Sicht ist diese von Luther übernommene und beibehaltene mittelalterliche Elimination 1. der Eigenständigkeit und Subsumierung des Bildergebotes

$8 \quad$ Zitiert bei Peters (1990:15).

9 G. Hoffmann, zitiert von Wenz (1996:253).

10 Surkau (1959:1186f.). 
unter das Abgöttergebot des ersten Gebotes, die auf Augustin zurückgeht und 2. die künstliche Aufspaltung des neunten und zehnten Gebotes wegen der Zehnzahl, nicht nur zu bedauern, sondern theologisch bedenklich, wenn sie auch aus historischer Sicht (vgl. Luthers Auseinandersetzung mit den Bilderstürmern in Wittenberg) damals plausibel erschienen sein mag. 11

In der spätmittelalterlichen und römisch-katholischen Kirche zur Zeit Luthers diagnostiziert dieser schweres Versagen und eklatantes Defizit gegenüber dem Katechismus. 12 Zwiefach ist das aktuelle römische Katechismusversagen. Zum einen kennt man den Katechismus nicht und zum andern lehrt man inn nicht: Bischöfe und Doktoren versagen hier elementar.13 Sie verweigern sich theoretisch und praktisch der Katechismusvermittlung. Es ist nicht zu akzeptieren, „dass kein Bischof, ja auch kein Doktor die Zehn Gebote recht verstanden noch gelehrt hat" (WA 21, 328,24f). Mit der Verweigerung des Katechismus geht der Verlust der apostolischen Lehre der alten Kirche einher. „Da lag die alte Lehre vom Glauben Christi, von der Liebe, vom Gebet, vom Kreuz, vom Trost in Trübsalen danieder. Ja es war kein Doktor in aller Welt, der den ganzen Katechismus, das ist das Vaterunser, Zehn Gebote und Glauben, gewusst hätte, geschweige, dass sie inn sollten verstehen und lehren." (WA 30 II, 301b,23-27.) Die doktrinale, pädagogische, ja existentielle Abwesenheit des Katechismus darf nicht prolongiert werden. Im Gegenteil: ihr muss energisch und effizient abgeholfen werden.

\section{Bedeutung des Katechismus}

Das Wort Katechismus hat bei Luther einen vierfachen Gebrauch: 1. Katechismus ist Elementarunterweisung im christlichen Glauben (vgl. WA 19, 76,2-5). Er ist eine instructio dessen, was man als

11 Vgl. von Loewenich (TRE 6,546-550).

12 „Die Papisten haben solche Mühe und Arbeit [das ist: den Katechismus zu treiben] geflohen, haben nur mit den Zinsregistern zu tun gehabt. Also ist das christliche Häuflein und die Gemeinde Gottes verlassen und versäumt worden." (Aurifaber, Tischreden, 156). Luther wäre mit größter Freude selbst nach Rom gelaufen, wenn er dort einen Artikel des Katechismus hätte hören können: „Ego Martin Luther cucurrissem libentissime Romam, si unum articulum psalmorum et cathechismi audire debuissem." (WA 32, 219,33f.)

13 „Solche Stücke (sc. des rechten Katechismus: Zehn Gebote, Vaterunser, Credo) hat nie ein Bischof behandelt und sind dazu von den Euren auch nie gründlich verstanden noch gelehrt" worden. (WA 30 II, 346,10-17.) 
Christ zu wissen hat (WA 19, 76,11). 2. Katechismus steht für Katechismusgottesdienst: Man „lasse das junge Volk auch zur Predigt gehen, [...], damit sie es hören, auslegen und verstehen lernen, was ein jedes [Katechismus-]Stück in sich habe, so, dass sie es auch aufsagen können, wie sie es gehört haben, und fein richtig antworten, wenn man sie fragt, auf dass es nicht ohne Nutz und Frucht gepredigt werde. Denn darum tun wir den Fleiß, den Katechismus oft vorzupredigen, damit man solches in die Jugend einbläue, nicht hoch noch gelehrt, sondern kurz und einfältig, auf dass es ihnen wohl eingehe und im Gedächtnis bleibe." (GK, BSLK 559,18-32.) In der Deutschen Messe (1526) hat Luther für Montag und Dienstag Katechismuspredigten vorgesehen. 14 3. Katechismus firmiert für Katechismuslehrstücke. „Diesen Unterricht [...] weiß ich nicht schlechter noch besser zu stellen, als er von Anfang der Christenheit bereit gestellt und bisher geblieben ist, nämlich: die drei Stücke: die Zehn Gebote, der Glaube und das Vaterunser. In diesen drei Stücken steht [...] kurzgefasst alles, was einem Christen notwendig ist zu wissen." (WA 19, 76,7-11.) Im Katechismus sind die Lehrstücke enthalten, die der Christ, wenn er denn ein solcher tatsächlich sein will, zu wissen und damit zu lernen hat. 4. Auch als Katechismusbuch wird der Begriff Katechismus bei Luther gebraucht. 15 Wobei hier das Schwergewicht auf dem Inhalt des Katechismusbuches liegt. Dieser in fünf Hauptstücke verortete Inhalt des Katechismus enthält die fundamentalen Essentials des christlichen Glaubens: Neben den „drei Hauptstücken“ (Dekalog, Credo und Vaterunser) ist im Katechismus zu reden „von unsern zwei Sakramenten, von Christus eingesetzt, davon auch ein jeder Christ gemeinen [ $=$ allgemein verständlichen] kurzen Unterricht haben muss, weil ohne dieselbigen keine Christen sein können“ (GK, BSLK 691,3-10). Albrecht Otto ist zuzustimmen, wenn er zum Gebrauch des Terminus "Katechismus“ bei Luther feststellt: „,'Katechismus' ist Unterricht in der christlichen Religion, Elementarunterricht im Christentum, zunächst als Handlung gedacht, dann als Sakrament, dass diese zwei Tage den Katechismus erhalten und inn stärken in seinem rechten Verstand." (WA 19, 79,17-20.) 
ein abgegrenzter Lehrstoff, dann als Bezeichnung eines Buchinhalts und schließlich eines Buches selbst“. 16

Luthers Schrifttum umfasst in der berühmten Weimaraner Werkausgabe über 125 Bände. Von dem vielen, was Luther geschrieben hat, sah er selbst nur weniges als erhaltenswert an. Wichtig war inm aber neben seiner schwergewichtigen Schrift über den unfreien Willen (De servo arbitrio) nur der Katechismus. 17 Sehr verbreitet war Luthers Kleiner Katechismus. Zu Luthers Lebzeiten erschien er in über sechzig Ausgaben. Noch im 16. Jahrhundert wurde er unter anderem ins Lateinische, Dänische, Französische, Polnische, Niederländische, Slowenische, Litauische, Altpreußische, Italienische und ins Arabische übertragen (WA 30 I, 782-800). 18

Mit Recht hat man das Reformationszeitalter "das katechetische Zeitalter der Kirchengeschichte" genannt. In keiner anderen Epoche hat es derart zahlreiche und vielfältige Versuche gegeben, die christliche Lehre neu zu formulieren, wie in der ersten Hälfte des 16. Jahrhunderts. Luthers Einfluss ist dabei bei den Katechismusversuchen unverkennbar. Im reformierten Bereich erlangte der Heidelberger Katechismus (1563) langfristige Geltung. „Unter allen Katechismen aber waren diejenigen Luthers die erfolgreichsten und wirkungsvollsten, insbesondere der Kleine Katechismus (1529)“. 19 Dankbar sind die lutherischen Kirchen für Luthers Kleinen Katechismus durch die Jahrhunderte hindurch gewesen.20 So schreibt 1883 der Giessener Theologieprofessor Johannes Gottschick: „Luthers Kleiner Katechismus, dieses schlichte, wenige Blätter füllende Büchlein, hat einen vollgültigen Anspruch darauf, in erster Linie mitgenannt zu werden, wenn wir uns die Fülle unschätzbarer Gaben vergegenwärtigen, für welche unsere evan-

16 Otto, Vorbemerkung, in: WA 30 I, 454.

17 „Nullum enim agnosco meum iustum librum, nisi forte de Servo arbitrio et Catechismum." (WA BR 8, 99,7f.)

18 „Die Zahl der Ausgaben seit dem 16. Jahrhundert allein in deutscher Sprache ist Legion - eine im Entstehen begriffene Bibliographie von Reinhard Junghans vermerkt für die Jahre 1750 bis 1850 an selbständigen Ausgaben, Abdrucken in Epistel- und Evangelienausgaben, Gesangbüchern und Bekenntnisschriften bisher etwa 3000 Titel." (Schilling, 2005:310.)

19 Schilling (2005:305).

20 Der neueste Kommentar zu Luthers Kleinem Katechismus stammt von Klaus Schwarzwäller (2000). 
gelische Kirche und unser deutsches Volk Gott dem Herr in diesem Mann zu danken hat." 21 Luthers Katechismus habe als echtes Volksbuch dem gemeinen Volk die positive Heilserkenntnis des Evangeliums eingepflanzt. $22 \mathrm{Er}$ besitze nicht $\mathrm{zu}$ übertreffende aktuelle Bedeutung. 23

Luther erachtet den Inhalt des Katechismus sehr hoch. Der den Dekalog, das Credo und das Vaterunser enthaltende Katechismus soll herrschen und bleiben. 24

\section{Genesis des Katechismus und die Katechismuspredigten}

Luthers Schrift von 1520 Eine kurze Form der Zehn Gebote, eine kurze Form des Glaubens, eine kurze Form des Vaterunsers (WA 7, 204-229), ist „so etwas wie die Keimzelle seiner katechetischen Literaturproduktion“. 25 Hier gibt er auch präzise und umfassend sein katechetisches Zielprogramm an: „Das ist nicht ohne besondere Ordnung Gottes geschehen, dass für den gemeinen Christenmenschen, der die Schrift nicht lesen kann, verordnet ist zu lehren und zu wissen die Zehn Gebote, den Glauben und Vaterunser, in welchen drei Stücken fürwahr alles, was in der Schrift steht und immer gepredigt werden kann, auch alles, was einem Christen notwendig ist zu wissen, gründlich und reichlich enthalten ist, [...] was inm notwendig zur Seligkeit ist. Denn drei Dinge sind dem Menschen notwendig zu wissen, damit er selig werden möge: Das

$21 \quad$ Gottschick (1883:1).

22 „Dass [...] die positive Heilserkenntnis der Reformation das bewusste Eigentum einer Kirche Christi, einer Gemeinde der Gläubigen wurde, dass sie nicht ein Vorrecht der Theologen blieb, dazu hat vor allem neben der deutschen Bibel und neben dem Kirchenlied der Kleine Katechismus geholfen. Als ein echtes Volksbuch hat er das Verständnis für das Evangelium in den Kreisen des gemeinen Mannes gepflanzt und ist so ein reicher Ersatz geworden für manchen Mangel in der äußern Gestalt der evangelischen, speziell lutherischen Kirche." (Gottschick, 1883:1f.)

23 Enthusiastisch verkündet Gottschick: „[...] auch heute noch (ist) eine bessere Grundlage des Unterrichts in der christlichen Heilswahrheit nicht nur nicht vorhanden, sondern auch nicht denkbar [...] als Luthers Kleiner Katechismus" (Gottschick, 1883:2).

24 "Catechismus dominabitur, id est, decalogus, symbolum, oratio dominica; wie wohl viele dawider legen, manebit tamen." (WA TR 1, 489,22f. [Nr. 966].) 
Erste, dass er wisse, was er tun und lassen soll. Zum andern, wenn er ( $=$ der Christenmensch) nun sieht, dass er es nichts tun noch lassen kann aus seinen Kräften, dass er wisse, wo er es nehmen, suchen und finden soll, damit er dasselbe tun und lassen möge. Zum dritten, dass er wisse, wie er es suchen und holen soll. Gleich als einem Kranken ist zum Ersten notwendig, dass er wisse, was seine Krankheit ist, was er kann oder nicht kann tun oder lassen. Danach ist es notwendig, dass er wisse, wo die Arzenei sei, die ihm helfe dazutun, was er tun und lassen kann, was ein gesunder Mensch (ist). Zum Dritten muss er sein Begehren, das Suchen und Holen oder Bringen lassen. Alsbald lehren die Gebote den Menschen, seine Krankheit zu erkennen, damit er sieht und empfindet, was er tun und nicht tun, lassen und nicht lassen kann, und erkennt sich als einen Sünder und bösen Menschen. Danach lehrt inn der Glaube [...], wo er die Arzenei, die Gnade, finden soll, die ihm hilft fromm zu werden, dass er die Gebote halte, und (der Glaube) erzeigt ihm Gott und seine Barmherzigkeit, in Christus erwiesen und angeboten. Zum Dritten lehrt inn das Vaterunser, wie er dieselben begehren, holen und zu sich bringen soll, nämlich mit ordentlichem demütigem tröstlichem Gebet; so wird es ihm gegeben, und wird danach durch die Erfüllung des Gebotes selig. Das sind die drei Dinge in der ganzen Schrift." (WA 7, 204,5-205,4.) Der Katechismus lehrt also die drei für den Menschen notwendigen soteriologischen Kerndinge der Heiligen Schrift: 1. Durch die Gebote wird dem Menschen zum einen das von Gott verordnete Tun und Lassen gesagt. Und zum anderen erkennt er durch diese, dass er diesen aus Eigenem nicht gerecht wird. 2. Das Credo zeigt dem Menschen den rettenden Ort. Das ist der Glaube, mittelst dessen der Mensch durch die von Gott gewährte Barmherzigkeit und Gnade Christi fromm und gerecht wird. 3. Das Vaterunser erweist als Gebet, wie der Mensch zu Gottes heilsbringendem Willen kommt.

Für die Entstehung von Luthers Katechismus spielen die Katechismuspredigten nicht nur eine entscheidende Rolle, sondern der Katechismus ist verdichtete summarische Katechismuspredigt. Predigten über den Dekalog, die Luther 1516/17 gehalten hatte, wurden 1518 publiziert (WA 1, 398-521). Wichtige Vorarbeiten für seine Katechismen waren Luthers Fastenpredigten von 1523 und die drei Katechismuspredigtreihen aus dem Jahre 1528. Ebenso Quell-Texte für die Entstehung von Luthers Katechismus waren seine Auslegung deutsch des Vaterunsers für die einfältigen Laien von 1519 (WA 2, 80-130) und Eine kurze Form der Zehn Gebote, des Glaubens und des Vaterunsers von 1520 (WA 7, 204-229), die Luther in leicht bearbeiteter Form in sein "Betbüchlein" von 1522 
(WA $10 \mathrm{II}, 375-407$ ) übernahm. 26 Aus Luthers Katechismuspredigten gingen 1529 seine beiden Katechismen hervor.

Das Verhältnis der Katechismuspredigten zum Katechismus erschöpft sich aber nicht in der genetischen Herkunft von diesem aus jenen. Für Luther ist der Katechismus Kernbestand des deutschen Gottesdienstes. Ohne guten Katechismus gelingt Gottesdienst nicht. „Zuerst ist im deutschen Gottesdienst ein klarer und kerniger, schlichter, einfacher, guter Katechismus notwendig." (WA 19, 76,1f.) Dieser dem Gottesdienst notwendige klare und kernige Katechismus ist keine reformatorische Neuerung, sondern er basiert auf dem seit der alten Kirche geläufigen Katechumenenunterricht mit den drei Hauptstücken: Zehn Gebote, Credo und Vaterunser. Allerdings bedarf er effizienter religionspädagogischer Vergegenwärtigung seitens der Pfarrer und Eltern, um essentialer Bestandteil christlichen aktuellen Gottesdienstes zu sein. 27

Ab Herbst 1528 fanden in Kursachsen verstärkt Visitationen der lutherischen Gemeinden statt. Sie offenbarten: 1. substantielle

26 Genauere Angaben zu Luthers Vorarbeiten für den Katechismus gibt Albrecht (1915:10ff.).

27 „Katechismus aber heißt ein Unterricht, mit dem man die Heiden, die Christen werden wollen, lehrt und unterweist, was sie im Christentum glauben, tun, lassen und wissen sollen. Daher hat man die Lehrjungen, die zu solchem Unterricht angenommen waren und den Glauben lernten, ehe man sie taufte, Katechumen genannt. Diesen Unterricht bzw. diese Unterweisung, weiß ich nicht schlichter oder besser aufzubauen, als er vom Anfang der Christenheit an aufgebaut und bisher geblieben ist, nämlich auf diese drei Stücke: die Zehn Gebote, der Glaube und das Vaterunser. In diesen drei Stücken steht schlicht und kurz fast alles, was ein Christ wissen muss. Dieser Unterricht muss nun so geschehen, - solange man noch keine abgesonderte Gemeinde hat -, dass diese zu gewissen Zeiten oder täglich, wie es erforderlich ist, auf der Kanzel vorgepredigt und daheim in den Häusern abends und morgens den Kindern und Gesinde, wenn man sie zu Christen machen will, vorgesagt und vorgelesen werden. Aber nicht nur so, dass sie Worte auswendig lernen und reden wie es bisher geschehen ist, sondern dass man sie von Stück zu Stück abfrage und sie antworten lasse, was ein jedes bedeutet und wie sie es verstehen. Kann man nicht alles auf einmal abfragen, so nehme man nur ein Stück vor und am folgenden Tag ein anderes. Denn wenn Eltern oder Erzieher der Jugend nicht selbst oder mit Hilfe anderer diese Mühe mit ihnen auf sich nehmen wollen, wird nimmermehr ein Katechismusunterricht eingerichtet werden [...].

Nämlich also soll man sie fragen: ,Was betest du?' Antwort: ,Das Vaterunser'. ,Was bedeutet es denn, dass du sprichst: ,Vater unser im Himmel'? Antwort: ,Dass Gott nicht ein irdischer, sondern ein himmlischer Vater ist, der uns im Himmel reich und selig machen will.'" (WA 19, 76,2-27.) Ähnlich soll man nach Luther (WA 19, 77,2ff.) mit dem Credo und den Zehn Geboten verfahren. 
Unkenntnis des christlichen Glaubens überhaupt, 2. fundamentales Missverständnis der christlichen Freiheit und 3. massiv verbreitete widerchristliche Lebensführung. Diese Missstände veranlassten Luther, seinen Kleinen Katechismus abzufassen. Die einzelnen Hauptstücke des Kleinen Katechismus erschienen zunächst als Plakatform. In Buchform zusammengefasst kam der Kleine Katechismus (mit Illustrationen) im Mai 1529 heraus.

Luther hat bekanntlich zwei Katechismen verfasst, den Kleinen und den Großen Katechismus. Großer Katechismus ist nicht Luthers Bezeichnung. Er nennt inn Deutscher Katechismus (vgl. WA 30 I, 481f.). Luther hatte im Mai, September und November 1528 in Wittenberg (in Vertretung für den Stadtpfarrer Johannes Bugenhagen) in drei Reihen Katechismuspredigten die fünf Hauptstücke behandelt (WA 30 I, 2-122). Diese Predigten dienten der unmittelbaren Abfassung des Großen Katechismus (= GK), der im April 1529 (also einem Monat vor dem Kleinen Katechismus [= KK]) erschien. 28

Großer und Kleiner Katechismus haben viel Gleichartiges: 29 1. Öfter werden GK und KK unter dem einen Namen Katechismus zusammengefasst. 2. Sie gehen beide aus den Katechismuspredigten von 1528 hervor. 3. Auslegungen der fünf Hauptstücke (für Kinder und Einfältige) sind beide. 4. Hausvätern und Pfarrern zugleich werden sie in die Hand gegeben. 5. Im KK und im GK werden die Pfarrer zur profilierten Vermittlung des Katechismusinhaltes angehalten. 6. Rechte Sakramentsunterweisung wird in beiden gefordert.

Trotz dieses Gleichartigen sind die Unterschiede von KK und GK nicht zu übersehen: ${ }^{30}$ 1. Als Lernbuch für Kinder, in Frageform und zum Auswendiglernen ist nur der KK bestimmt. 2. Während der Arbeit am GK entsteht erst der KK. 3. Auf schlichte positive Aussagen orientiert sich mehr der KK als der GK. 4. Der Beschäftigung mit dem GK soll die Einprägung des KK vorangehen. 5. Der GK nimmt mehr aus den Katechismuspredigten von 1528 auf. Das gilt auch hinsichtlich der Polemik gegen Rom und die Schwarm-

28 Die von Vincentius Obsopöus lateinische Übersetzung des Großen Katechismus erschien 1529.

Vgl. zum Folgenden: Albrecht in WA 30 I, $549 f$.

Vgl. zum Folgenden: Albrecht in WA 30 I, $549 f$. 
geister. 6. Etliches aus dem KK wird im GK einer Klärung zugeführt. Das geschieht beispielsweise hinsichtlich des 1. Gebotes (vertrauen). Auch 3. und 4. Gebot werden näher erklärt, ebenso wie im 2. Artikel der Begriff des Herrn und der des Heiligen im 3. Artikel. 7. Beide Katechismen sind etwas Selbständiges.

\section{Katechismus als brevis summarium der Schrift, Laienbibel und instructio}

Der Katechismus hat aus sich heraus nicht originäre Ursprünglichkeit. Er ist und wirkt nicht aus sich selbst. Er ist bewusst und profiliert etwas, das sich anderem verdankt. Ja, er hat nur dann Sinn, wenn er von anderem her ist und dieses andere präzise artikuliert und adressiert. Seine Grundlage, auf der er steht, ist allein die Heilige Schrift. Das Sola-scriptura ist inm essentiell normativ. Luther nennt darum auch den Katechismus „der ganzen Heiligen Schrift kurzer Auszug" (GK, WA 30 I, 128,29f.). Der Katechismus ist nicht eine beliebige Zusammenfassung (brevis summarium bzw. summaria descriptio) ${ }^{31}$ der Heiligen Schrift, sondern deren soteriologisch fokussierte. Qua dieser soteriologischen Fokussierung ist der Katechismus Laienbibel: „Der Katechismus ist der Laien Bibel, darin der ganze Inhalt christlicher Lehre, die einem jeden Christen zur Seligkeit zu wissen nötig (ist), enthalten (ist)." (WA TR 5, 581,3032, Nr. 6288.) Er ist als Laienbibel zugleich Kinderpredigt. Luther nennt 1528 den Katechismus „die Kinder-Predigt oder der Laien Biblia" (WA 30 I, 27,26).

Damit der Katechismus dieses sein kann, muss er gepredigt werden. Der Katechismus verdankt sich genetisch und theologisch sachlich der Laienbibel. 32 Das profilierte Katechismuswissen seiner Kirchenglieder war dem reformatorischen Glauben essentiell notwendig. Dieser begründete seinen Glauben nicht mehr wie die römische Kirche primär autoritativ, sondern auf Grund eines vollbewussten Glaubens. Johannes Gottschick drückte es zu Recht so aus: „Konnte die katholische Kirche sich mit der fides implicita, dem Gehorsam gegen die formelle Autorität der Kirche begnügen,

31 GK (Großer Katechismus), BSLK, 552,35-38.

32 „Für das Verständnis von Luthers Katechismen ist entscheidend, dass sie aus seiner Predigttätigkeit herausgewachsen sind. 1516/17 predigte Luther über den Dekalog, später auch über das Vaterunser und Glaubensbekenntnis und begründete 1523 die Gewohnheit der jährlichen Katechismuspredigten." (Surkau, 1959:1182.) 
die evangelische Kirche musste das Ihre tun, um ihre Glieder zur fides explicita, zu dem seines Inhaltes und seines Rechtes vollbewußten Glauben zu erziehen." 33 So ist für Luther der Katechismus das Fundament, darauf man bauen soll (WA TR 2, 522,29, Nr. 2554 b). Solide katechetische Gründung dient der oikodome (Auferbauung) der christlichen Gemeinde. Wird dieses Fundament nicht essentiell gewusst, verkommt die christliche Gemeinde zur ignoranten, ihren Glauben nicht kennenden religiösen Infantilgemeinschaft, die für sich selbst und andere unnütz, ja schädlich ist. Als Grundlage des voll bewussten Glaubens ist also effiziente Katechismuskultur erforderlich.

Der Katechismus ist christliche Unterweisung (christiana instructio). $\mathrm{Er}$ ist jedermann zu unterrichten. Als instructio kann der Katechismus der christlichen Erbauung dienen. Wer den Katechismus nicht per instructionem zugeeignet bekommt, wird seinen wesentlichen Inhalt nicht aufnehmen können. „Die Predigt des Katechismus ist deshalb zu unternehmen, damit sie eine Unterweisung (instructio) für Knaben und Einfache (sei), weil der Katechismus Unterweisung heißt. Jeder Christ muss notwendigerweise den Katechismus kennen. Wer inn ignoriert, kann nicht zur Zahl der Christen gerechnet werden. Wie der Baumeister, der seine Kunst nicht kennt, herausgeworfen wird. Also lernen die Knaben den Katechismus. Es sollen sich auch die Väter und Herren bemühen, damit Kinder und Familie, das, was sich auf die doctrina Catechismi erstreckt, lernen. Und sie sollen siebenmal wenigstens, anhören, ob Kinder und Familie diese können oder nicht. Wenn sie sie nicht kennen, sollen sie urgieren, dass sie lernen. Es werden viele Erwachsene gefunden, die nichts von diesen (sc. doctrinae Catechismi) kennen. Und dennoch genießen/gebrauchen (utuntur) sie alles, was Christen genießen." (WA 30 I, 2,2-14.) Luther betont stark den instructioCharakter. Tüchtig gemacht soll der Christ durch den Unterricht des Katechismus werden. Ohne diesen Unterricht kann man nicht Christ genannt werden und auch nicht zu den Sakramenten zugelassen werden. In Luthers Vorrede zum Grossen Katechismus von 1529 heißt es dementsprechend: „Diese Predigt ist dazu geordnet [...], dass sie sei ein Unterricht für die Kinder und Einfältigen. Darum heißt sie auch von Alters her auf Griechisch Katechismus, das ist eine Kinderlehre, die ein jeder Christ notwendiger Weise wissen soll, also dass, wer solches nicht weiß, nicht unter die Christen gezählt und zu keinem Sakrament zugelassen werde. Gleichwie man einen 
Handwerksmann, der seines Handwerks Recht und Gebrauch nicht weiß, heraus wirft und für untüchtig hält. Deshalb soll man junge Leute die Stücke, die in den Katechismus oder Kinderpredigt gehören, gut und fertig lernen lassen und mit Fleiß darin üben und treiben. Darum ist auch ein jeder Hausvater schuldig, dass er wenigstens einmal die Woche seine Kinder und Gesinde der Reihe nach abfrage und verhöre, was sie davon wissen oder lernen. Und, wo sie es nicht können, mit Ernst dazu anhalte." Es gibt auch „einfache, alte, betagte Leute [...], die hiervon gar nichts [...] wissen, gehen jedoch dennoch zu Taufe und Sakrament und gebrauchen alles, was die Christen haben; so doch die, die zum Sakrament gehen, billigerweise mehr wissen und vollkommeneren Verstand aller christlichen Lehre haben sollen als die Kinder und neuen Schüler." Man soll den Katechismus (Gebote, Credo, Vaterunser) treiben "solange bis man sich in dem selben wohl übe und bewandert werde, beide Jung und Alt, die Christen heißen und sein wollen“ (BSLK 553,33-554,33).

Katechismus heißt also Katechismusunterricht. Ohne diesen ist jener nicht adäquat zu verorten. Das „Muss“ des Katechismusunterrichtes ist auch der nicht hoch genug zu bewertende Anfang einer allgemeinen, also jeden betreffenden Schulpflicht: Im Katechismusunterricht der Reformationszeit hat man den „Anfang zu einem allgemeinen Volksschulunterricht und im Katechismuszwang den Beginn des Schulzwanges" zu konstatieren. 34

„Handfeste christlich-kirchliche Volkserziehung“ konstatiert Gottfried Holtz in Luthers Katechismen. Auf Grund der Erkenntnisse aus den ersten reformatorischen Visitationen setze Luther im Katechismus auf „Volkspädagogische Gesichtspunkte“, nachdem er in Folge der ersten Kirchenvisitationen erkannte, dass die „Sprache der religiösen Innerlichkeit und die Polemik gegen Rom und die Schwärmer nicht genügten, um das Volk zur Umkehr zu bewegen."35

Effektiver Aneignung des Katechismus in entsprechenden instructiones ist der Besuch insbesondere der Katechismuspredigten sehr förderlich. Fleißig soll der Katechismus gepredigt 36 und die Katechismuspredigten besucht werden. Die Prediger sollen nicht 
müde werden, Katechismuspredigten zu halten. Werden die Worte des Katechismus gewusst, kann er mit Nutzen für jedermann rezipiert werden. 37

\section{Verbreitete Verachtung des Katechismus bei Pfarrern und Predigern 38}

Viele Pfarrer und Prediger sind stinkend faul. Freßlinge und Bauchdiener sind sie, lesen keine Bücher und treiben auch den Katechismus nicht. Sie sind durch böse Verderben generierende fleischliche Freiheit und Faulheit irregeleitet, haben sich in diesen eingerichtet. Als Sauhirten und Hundeknechte vernachlässigen und diskreditieren sie das kirchliche Amt. Luther geißelt grob und kräftig diese Missstände. „Dass wir den Katechismus so fest treiben [...], haben wir nicht geringe Ursachen, weil wir sehen, dass leider viele Prediger und Pfarrer hierin sehr säumig sind und verachten beide ihr Amt und diese Lehre, etliche aus großer Gelehrsamkeit, etliche aber aus lauter Faulheit und Bauchsorge." Sie denken „nichts [anderes] zu tun, als die Güter zu gebrauchen; weil sie leben; wie sie es unter dem Papsttum gewohnt waren." Sie lesen keine Bücher. „Ach das sind allzumal schändliche Freßlinge und Bauchdiener (Röm. 16,18), die von Rechts wegen Sauhirten oder Hundeknechte sein sollten“, aber nicht Seelsorger und Pfarrer. Obwohl sie des Breviergebetes der sieben kanonischen Horen (Stundengebete) ledig sind, lesen sie nun nicht - wie es sein sollte - „morgens, mittags und abends [...] aus dem Katechismus, dem Betbüchlein (sc. Luthers von 1522) [...], der Bibel", beten kein „Vaterunser für sich und ihre Pfarrkinder". "Gleichwie die Säue und Hunde behalten sie nicht mehr vom Evangelium als solche faule schädliche, schändliche, fleischliche Freiheit." (GK, BSLK 545,1-546,31.)

37 „Es soll aber nicht an dem genug sein, dass man es [= das Katechismuswort] alleine den Worten nach fasse und aufsagen könnte, sondern lasse das junge Volk auch zur Predigt gehen, besonders zu der Zeit, die dem Katechismus zugeordnet [ist], dass sie es hören, auslegen und verstehen lernen, was ein jedes Stück in sich habe, also, dass sie es auch können aufsagen, wie sie es gehört haben, und fein richtig antworten, wenn man sie fragt, auf dass es nicht ohne Nutzen und Frucht gepredigt werde. Denn darum tun wir den Fleiß, den Katechismus oft vorzupredigen, dass man solches in die Jugend einbläue, nicht hoch noch gelehrt, sondern kurz und aufs Einfältigste, auf dass es innen wohl eingehe und im Gedächtnis bleibe." (GK, BSLK 559, 16-32.)

38 „Der Prediger ist nur auf den Predigtdienst beschränkt, während der Pfarrer daneben noch die Kasualien ausübt, also der Träger der gesamten Seelsorge ist." (BSLK 545, Anm. 2.) 
Der Katechismus wird bei Pfarrern - und zwar sowohl bei gemeinen (= ungelehrten) als auch bei gelehrten 39 - und geizigen Adligen nicht nur nicht betrieben, er wird als primitiv und als von zu großer Schlichtheit geprägt verschmäht. Als „schlichte, geringe Lehre“ wird er verachtet, in den Winkel geworfen, da man schon alles kenne. Sie „schämen (sich)“, den Katechismus „zu lesen. Ja, man findet wohl etliche Rülzen und Flize (= grobe Menschen und Geizhälse) auch unter dem Adel, die vorgeben man bedürfe hinfort weder Pfarrer noch Prediger, man habe es in Büchern und könne es von sich selber wohl lernen“. (GK, BSLK 547,9-21.)

Die Folgen dieser Missachtung des Katechismus hatte Luther als Visitator $\mathbf{4 0}$ kennengelernt. Sie erschütterten und nötigen ihn zum Handeln. Die „klägliche elende Not“, die er hier erfahren hatte, zwingt inn, um dieser abzuhelfen, den Kleinen Katechismus zu schreiben. „Diesen Katechismus oder christliche Lehre in solche, kleine, schlichte, einfältige Form zu stellen, hat mich gezwungen [...] die klägliche, elende Not, die ich neulich erfahren habe, als ich auch ein Visitator war. Hilf, lieber Gott, wie manchen Jammer habe ich gesehen, dass der gemeine Mann so gar nichts von der christlichen Lehre weiß, besonders auf den Dörfern, und leider sind viele Pfarrer fast ungeschickt und untüchtig zu lehren und sollen doch alle Christen heißen, getauft sein und die heiligen Sakramente genießen, können weder Vaterunser noch den Glauben noch Zehn Gebote, leben dahin wie das liebe Vieh und unvernünftige Säue, und, wo das Evangelium gekommen ist, dennoch fein gelernt haben, alle Freiheit meisterlich zu missbrauchen." (KK, BSLK 501,8-502,9.) Der kirchlichen Obrigkeit, den Bischöfen wirft Luther vor, dass sie die Nachfolge Christi verweigert hätten, indem sie mit der Katechismusverweigerung dem Volk die Grundessentials des christlichen Glaubens vorenthielten. $\mathbf{4 1}$

39 Luther kennt gemeine (= ungelehrte) und gelehrte Pfarrer. So schreibt er 1530: „Lateinisch müssen die gemeinen Pfarrer und Prediger können und dürfen es nicht entbehren; so wenig wie die gelehrten des Griechischen und Hebräischen nicht entbehren sollen." (WA 30 II, 547,19-21; vgl. auch BSLK 501, Anm. 1.)

40 Luther, zum Visitator von Kursachsen und Meißen bestellt, visitierte vom 22.10.1528-9.1.1529.

41 „Oh, Ihr Bischöfe, wie wollt ihr es vor Christus verantworten, dass ihr das Volk so schändlich habt lassen gehen und Euer Amt nicht einen Augenblick je beweiset? Dass Euch alles Unglück fliehe! Verbietet einerlei Gestalt und dringt auf Euere Menschengesetze, fragt aber dieweil nichts danach, ob sie das Vaterunser, Glauben, Zehn Gebote oder irgendein Gotteswort könnten. Ach und Wehe über Euren Hals ewiglich." (KK, BSLK, 502,9-19.) 
Luther fordert die Pfarrer auf, sich ihres „Amtes von Herzen anzunehmen" und damit des innen anvertrauten Volkes sich zu erbarmen, damit der Katechismus unter das Volk gebracht wird und die Zehn Gebote, das Credo, das Vaterunser und die Sakramente mit dem einfachen und jungen Volke in einheitlicher konstanter (nicht ständig wechselnder) Form eingeprägt und gelernt werden (KK, BSLK 502,28-38). Den Gelehrten gegenüber sei es möglich, den Katechismus buntkraus (= vielgestaltig) und meisterlich zu lehren, wie es dem Pfarrer seiner Gelehrsamkeit entsprechend möglich ist (KK, BSLK 503,13-16).

\section{Notbischöfe, Pfarrer, Hausväter, Eltern und auch Gelehrte haben den Katechismus zu treiben und bleiben selbst Schüler des Katechismus}

Nachdem das „Papsttum und seine Rotte“ im Bischofsamt versagt haben, ist es Pflicht der weltlichen Obrigkeiten als Notbischöfe (vgl. WA 26, 197,12-198,5) dafür zu sorgen, dass das Evangelium in Kirche und Schule verkündigt wird.42 Die obrigkeitlichen Notbischöfe sorgen durch die von innen angeordneten Visitationen, bei denen der Katechismus eine fundamentale Rolle spielt, dafür, dass "Gottes Willen dem Evangelium zugute und den elenden Christen [...] zu Nutz und Heil" (WA 26, 197, 27f.) geschieht. Es ist also Aufgabe der Notbischöfe, den Katechismus zum Wohl und Heil der Christenmenschen zu treiben. Die Katechismuslehre ist für Luther von der Obrigkeit notwendig zu verordnende Lehre, zu allgemeinem Nutzen und wegen des dem Evangelium gemäßen Heils.

Sich auf Deuteronomium 6,7f. berufend fordert Luther alle Pfarrer auf, täglich den Katechismus zu lernen und zu lehren: „Und ob solches nicht genug wäre zur Vermahnung, den Katechismus täglich zu lesen, so sollte doch uns allein genug zwingen Gottes Gebot, der [Gott] Dtn. 6,7f. ernsthaft gebietet, dass man soll sein Gebot sitzend, gehend, stehend, liegend, aufstehend immer bedenken und gleich wie ein stetiges Mal und Zeichen vor Augen und in Händen

42 „Müssen doch unsere weltliche Herrschaften jetzt Notbischöfe sein und uns Pfarrern und Predigern (nachdem der Papst und seine Rotte nichts dazu-, sondern dagegen tut) schützen und helfen, dass wir predigen, Kirchen und Schulen dienen können, wie Jesaja $(49,23)$ sagt: [...], Könige sollen dich nähren und Königinnen sollen dich säugen.' Wie sie denn vorzeiten fast allzu reichlich getan [und] noch tun, und wo das Evangelium sie fromm gemacht hat." (WA 53, 255,5-10.) 
haben"“ (GK, BSLK 550,37-551,6). Der Kleine Katechismus ist ausdrücklich für „Pfarrer und Prediger" (KK, BSLK 501,3) dediziert. Sie haben auch wegen des kirchlichen Amtes, in das sie berufen sind, den Katechismus zu treiben: „Darum bitte ich um Gottes willen euch alle, meine lieben Herrn und Brüder, so Pfarrer und Prediger sind, [ihr] wollet euch eures Amts von Herzen annehmen, euch erbarmen über euer Volk, das euch anbefohlen ist, und uns helfen, den Katechismus in die Leute, besonders in das junge Volk zu bringen." (KK, BSLK 502,28-34.) Zunächst sollten Pfarrer dem Volk den Kleinen Katechismus lehren, danach sich mit dem Großen Katechismus beschäftigen und den Ertrag dieser Beschäftigung unter das Volk bringen. $\mathbf{4 3}$

In der Pflicht, den Katechismus zu treiben, werden von Luther auch insbesondere die Hausväter genommen. Das rührt daher, dass „ein Vater eigentlich ein Bischof und Pfarrer seines Hauses sein soll" (WA 24,223,11). Den Vätern kommen hinsichtlich ihrer Hausfamilien wesentliche Aufgaben zu: „Ein Vater soll sein Kind strafen wie ein Richter, lehren wie ein Doktor, ihm predigen wie ein Pfarrer oder Bischof." (WA 16, 504,12-14.) Höchste Relevanz haben und größte Verantwortung tragen Eltern bei der Glaubens- und Lebensvermittlung ihrer Kinder. „Gewiss sind Vater und Mutter für die Kinder Apostel, Bischof und Pfarrer, weil sie innen das Evangelium verkündigen. [...] es gibt keine größere und edlere Gewalt auf Erden als die der Eltern über ihre Kinder, zumal sie geistliche und weltliche Gewalt über sie haben." (WA 10 II, 301,23-27.) Jedoch ist hier klar zu differenzieren. Eltern haben endliche irdische Gewalt, „denn in göttlichen Sachen sollen weder Vater noch Mutter, geschweige denn ein Bischof oder irgendein Mensch, sondern allein Gottes Wort lehren und führen" (WA 17 II, 67,11-13). Gebieten, lehren, bitten und verführen Eltern, „etwas gegen Gott und Gottes Dienst zu tun [...], so sollst du ihnen sagen: Was haben ich und du miteinander zu tun?" (WA 17 II, 67,13-17). Eltern sind auch schuldige Menschen, und aus diesem Grunde sind sie „von Gott gemacht, dass sie die Kindern nicht nach ihrem Gutdünken und eigener Andacht lehren und zu Gott führen sollen, sondern nach den Geboten Gottes“, gemäß Gottes Gebot (vgl. Eph. 6,4), und nicht nach der Eltern „eigen Ding" (WA 17 II, 67,19-24). Hier gilt das Gebot des göttlichen Kyrios Christus. Auf ihn ist zu hören (WA 17 II, 67,25ff). „Vater und großen Katechismus für dich und gib innen auch reichen weiteren Verstand." (KK, BSLK 504,35-39.) 
Mutter können an ihren Kindern das Himmelreich“, aber auch „die Hölle verdienen" (WA 16, 504,16-18). Treu und gerecht hat der Familienvater sein Amt auszuführen (WA 44, 657,9-15). Vater und Mutter haben als solche ein heiliges Amt: „Bist du Vater, Mutter: glaube an Jesus Christus, so bist du ein heiliger Vater und eine heilige Mutter. Verhöre des Morgens deine Kinder, lass sie beten, strafe, stäupe sie. Siehe, wie es im Haus zugeht und wie man kocht, das sind lauter heilige Werke, denn du bist dazu berufen. Das heißt ein heiliges Leben, welches in Gottes Wort und in der Berufung dahergeht." (WA 37, 480,4-8.) Hausväter haben die Pflicht, dass der Katechismus in ihren Häusern gelehrt und gelernt wird. Der Katechismusunterricht im Haus, für den der Hausvater zuständig ist, besteht im kontrollierten Abfragen und Üben der Katechismusstücke. Dieses ist zumindest einmal in der Woche konkret durchzuführen: „Ein jeder Hausvater ist schuldig, dass er zum wenigstens einmal in der Woche seine Kinder und Gesinde der Reihe nach abfrage und verhöre, was sie davon [Katechismus] wissen und lernen und, wenn sie es nicht konnten, mit Ernst dazu anhalte." (GK, BSLK 554,11-16.) Der Hausvater hat darauf zu achten, dass der Katechismus gut und ganz mit Fleiß geübt und getrieben wird (GK, BSLK 554,10f). Insbesondere gilt das für junge Leute, aber nicht nur für sie. Denn es sind viele Erwachsene und alte Menschen, die kaum etwas oder gar nichts wissen vom Katechismus und christlichem Glauben (GK, BSLK 554,18ff).

Hoch wertet Luther die Katechismusvermittlung durch Eltern und Hausherrn in der Hausgemeinschaft. Ohne diese bleibt die katechetische Vermittlung der Pfarrer ohne Ertrag. „Nur wenn ihr Eltern und Hausherrn uns [Predigern] helft, erreichen wir etwas mit unserer Predigt. Wenn ich auch das ganze Jahr über predige, kommt die Familie herein, sieht die Bilder an, die Fenster der Kirche, etc. Wer ein guter Bürger [des Reiches Gottes] ist, der muss die Seinen nötigen etc. [den Katechismus zu lernen] und soll innen kein Brot geben, außer [sie lernen den Katechismus]. Und wenn die Familie murrt, dann schlag sie mit der Tür [vor den Arsch]." (WA 30 I, 57,12-16.) Eltern und Obrigkeit haben diesbezüglich auch die Pflicht, auf den Schulbesuch der Heranwachsenden zu achten. "Obrigkeit und Eltern“ sollen so unterwiesen werden, „dass sie wohl regieren“ und „schuldig sind“, „Kinder zur Schule schicken“. Und „es nicht zu tun“, ist „eine verfluchte Sünde“ (KK, BSLK 505,19-24).

Notwendig ist jedem, auch dem Gelehrten, tägliches Katechismustreiben. Luther geißelt diejenigen, die meinen wegen ihrer hohen Gelehrsamkeit auf dieses verzichten zu können und nicht mehr 
Schüler des Katechismus sein wollen: „Ich bin auch ein Doktor und Prediger, ja so gelehrt und erfahren, wie alle die sein mögen, die solche Vermessenheit und Sicherheit haben. Dennoch tue ich wie ein Kind, das man den Katechismus lehrt und lese und spreche auch von Wort zu Wort des Morgens und wenn ich Zeit habe, das Vaterunser, Zehn Gebote, Glaube, Psalmen etc. und muss noch täglich dazu lesen und studieren und kann dennoch nicht bestehen, wie ich gerne wollte, und muss ein Kind und Schüler des Katechismus bleiben und bleibe es auch gerne. Und diese feinen stolzen Gesellen wollen mit einem Überlesen sofort Doktor über alle Doktoren sein, alles können und nichts mehr bedürfen." (GK, BSLK 547,29-548,9.) Wer kein Schüler des Katechismus sein will, verachtet 1. Gott und sein Wort, 2. sein Amt und 3. „des Volkes Seele" (GK, BSLK 548,11-13). Alle Menschen, auch die Gelehrten, sind Katechismusanfänger, die das $A B C$ des Katechismus zu lernen haben (GK, BSLK 548,15f.). Je mehr man sich mit dem Katechismus beschäftigt, ihm nachsinnt, desto mehr wird man seinen Reichtum erkennen und nach ihm hungern und dürsten. 44

Der den Pastoren von der Gemeinde anvertraute Dienst der Katechismusverbreitung trägt nach Luther auch ekklesiologischen Ertrag. Er bewirkt nämlich, dass junge Menschen Raum in der Kirche finden und multipliziert werden. $\mathbf{4 5}$ Außerdem schafft intensive Katechismusaneignung "Lust zum Sakrament" durch das Hören auf das Wort (WA 34 II, 335,19-23).

Der Katechismus ist das ganze Jahr hindurch zu lehren und zwar als ganzer Katechismus. Die Katechismusverkündigung ist öffentlich für jeden, der den Katechismus hören und lernen will: „Wir predigen

„Darum bitte ich [...] alle Christen, besonders die Pfarrer und Prediger, sie wollten nicht zu früh Doctores sein und alles Wissen sich dünken lassen [...], sondern sich täglich wohl darinnen üben und immer treiben [...], lesen, lehren, lernen, denken und nachsinnen und nicht ablassen, solange, bis sie erfahren und gewiss werden, dass sie den Teufel tot gelehrt haben und gelehrter geworden sind, als Gott selber ist und alle seine Heiligen. Werden sie solchen Fleiß tun, so [...] sollen sie es auch inne werden, welche Frucht sie erlangen werden und wie feine Leute Gott aus innen machen wird, dass sie mit der Zeit selbst fein bekennen sollen, dass je länger und mehr sie den Katechismus treiben, je weniger sie davon wissen und je mehr daran zu lernen haben, und wird innen als den Hungrigen und Durstenden dann allererst recht schmecken, das sie jetzt aus großer Fülle und Überdruss nicht riechen mögen. Da gebe Gott seine Gnade zu. Amen." (GK, BSLK 552,38-553,24.) generent novam prolem in ecclesia." (WA 31 II, 763,19f.) 
den ganzen Katechismus das ganze Jahr hindurch. Wer ihn hören will, kann ihn kennen lernen." (WA 41, 470,27f.)

Arrogante, „überdrüssige, vermessene Heilige“ sind diejenigen, die das tägliche Lesen und Lernen des Katechismus verweigern. Sie "halten sich selbst viel gelehrter, als Gott selbst ist mit allen seinen heiligen Engeln, Propheten und allen Christen“ (GK, BSLK 551,2730). An Gott freveln sie und stellen sich über inn und alle Christen mit aller ihrer selbstischen Gelehrsamkeit. So aber erweisen sich diese "Dunkelmeister" mit ihrem „giftigen Geschmeiß [Ansteckungsstoff]" als durch den Teufel totgelehrte Gelehrte (GK, BSLK 553,39), da Gott selbst den Katechismus nicht nur nicht verachtet, sondern ein den Katechismus Lehrender ist: „Denn weil Gott sich selbst nicht schämt, solches [= den Katechismus] täglich zu lehren, als derjenige, der nichts Besseres wisse zu lehren, und immer solches gleich lehrt und nichts Neues noch anderes [sich] vornimmt" (GK, BSLK 551,33-38). Dass Gott ein den Katechismus Lehrender ist, bei der dort verbrieften Wahrheit bleibt und sie nicht verändert, ist ein sehr kühner Gedanke Luthers, der dessen höchste theologische Wertung des Katechismus dokumentiert. Schüler des Katechismus zu bleiben, ihn fleißig täglich zu treiben, ist für Luther 1. höchste theologische Auszeichnung, 2. Einschärfung des Wortes Gottes und 3. zugleich Quelle Lebensrost beseitigenden herzerfrischenden Lebens. 46

\section{Pneumatologisch-soteriologischer Ertrag und Schutz vor dem Bösen}

Beim Lesen, Reden und Bedenken des Katechismus ist der Heilige Geist gegenwärtig. Der pneumatologischen Vergegenwärtigung durch den Katechismus darf kein Christ, um seines soteriologischen Christusglaubens willen entfliehen, denn beim täglichen Treiben des Katechismus bewirkt der Heilige Geist die Vergegenwärtigung Christi in unserer Mitte: „Deshalb bitte ich solche faulen Wänste

„Ich bin auch ein Theologe und habe in mancherlei Gefahren die Heilige Schrift doch so einigermaßen gelesen und verfüge über einige Erfahrung. Doch fühle ich mich solcher Gabe wegen nicht so erhaben, dass ich nicht täglich wie die Kinder den Katechismus, d.h. die Zehn Gebote, das Glaubensbekenntnis (und das Vaterunser) bei mir betete und mit ganzem Herzen betrachtete, dass ich nicht nur die Worte herunterhaspele, sondern dass ich darüber nachdenke, was die einzelnen Worte sagen wollen [...] Denn das Wort ist uns von Gott dazu gegeben, dass wir es uns - wie 5. Mose 6,7 sagt - einschärfen sollen und uns darin üben. Ohne diese tägliche Übung setzen unsere Herzen gleichsam Rost an, dass wir uns selbst damit vernichten." (WA 40 III, 192,16-25.) 
oder vermessene Heiligen, sie wollten sich um Gottes Willen überzeugen lassen und glauben, dass sie wahrlich nicht so gelehrt und hohe Doktoren sind, wie sie sich lassen dünken, und nimmermehr gedenken, dass sie diese [Katechismus] Stücke ausgelernt haben oder aller Dinge genug wissen, ob sie es gleichwohl dünkt, dass sie es allzu(mal) wohl können. Denn, ob sie es gleich allerdings aufs Allerbeste wüssten und könnten (das doch nicht möglich ist in diesem Leben), so ist doch mancherlei Nutzen und Frucht darinnen, wenn man es täglich liest und übt mit Gedanken und Reden, nämlich: dass der Heilige Geist bei solchem Lesen, Reden und Gedenken gegenwärtig ist und immer neu und mehr Licht und Andacht dazu gibt, dass es immer besser und besser schmeckt und eingeht, wie Christus auch Matthäus 18,20 verheißt: ,Wo zwei oder drei in meinem Namen versammelt sind, da bin ich in ihrer Mitte.'“ (GK, BSLK 548,31-549,16.)

Der Katechismus hat soteriologische Suffizienz, denn in seinen drei Hauptstücken (Dekalog, Credo, Vaterunser,) ist „fürwahr alles, was in der Schrift und immer gepredigt werden mag, auch alles, was einem Christen notwendig zur Seligkeit ist zu wissen, gründlich und überreichlich enthalten" (WA 7, 203,8-11.13). Wobei hier für Luther der fundamentale Unterschied zwischen Dekalog und Glauben zu beachtet ist und Gebot und Glaube nicht verwechselt werden dürfen in Bezug auf das, was sie theologisch leisten. Ihr jeweiliges theologisches Profil ist unbedingt zu beachten, um theologisch nicht in die Irre zu gehen. Luther sagt, dass „der Glaube eine ganz andere Lehre ist als die Zehn Gebote. Denn jene (= die Zehn Gebote) lehren wohl, was wir tun sollen, diese (= die Glaubensartikel) aber sagen uns, was uns Gott tue und gebe. Die Zehn Gebote sind auch ohnehin in aller Menschen Herzen geschrieben [vgl. Röm. 2,15]. 47 Den Glauben aber kann keine menschliche Klugheit begreifen und muss allein vom Heiligen Geist gelehrt werden. Darum macht jene Lehre (sc. von den Zehn Gebote) noch keinen Christen, denn es bleibt noch immer Gottes Zorn und Ungnade über uns, weil wir [...] nicht halten können, was Gott von uns fordert. Aber diese [sc. Lehre vom Glauben] bringt nichts als nur Gnade, macht uns fromm und Gott angenehm. Denn durch diese Erkenntnis kriegen wir Lust und Liebe zu allen Geboten Gottes, weil wir hier sehen, wie sich Gott ganz und gar mit allem, was er hat und vermag, uns gibt zu Hilfe gentiles, sed non e coelo haben's sich geholt ut Judaei“" (WA 16, 372,1-3). 
und Beistand, die Zehn Gebote zu halten: der Vater alle Kreaturen, Christus alle seine Werke, der heilige Geist alle seine Gaben. " (GK, BSLK 661,21-42.)

Aus dem Glauben folgt also das Tun der Zehn Gebote; und zwar in dieser Reihenfolge, nicht umgekehrt. Das Tun der Gebote kreiert nicht den Glauben, sondern der Glaube als das Primäre ermöglicht das Tun als das notwendig Sekundäre. „(D)er Glaube legt uns alles vor, was wir von Gott erwarten und empfangen müssen, und [...] ihn (= Gott) ganz erkennen lehrt. Welches eben dazu dienen soll, dass wir dasselbige tun können, was wir laut den Zehn Geboten tun sollen. Denn sie sind [...] so hoch gestellt, dass aller Menschen Vermögen viel zu gering und schwach ist, dieselbigen zu halten. Darum ist dieses Stück [...] notwendig zu lernen, dass man wisse, wie man dazu komme, woher und wodurch solche Kraft zu nehmen sei. Denn, wenn wir aus eigenen Kräften die Zehn Gebote halten könnten, wie sie zu halten sind, bedürfen wir nichts weiter, weder Glauben noch Vaterunser." (GK, BSLK 646,6-22.)

Katechismus treiben hat die Frucht und den Nutzen, dem Bösen, dem Teufel zu widerstehen. Durch das Leben, Lernen, Meditieren des Katechismus werden wir auf Gottes Wort orientiert. Und wo Gottes Wort Raum hat, verdampft das Böse. Katechismus-treiben "hilft über die Maßen gewaltig gegen den Teufel, Welt, Fleisch und alle bösen Gedanken, wenn man mit Gottes Wort umgeht, davon redet und darüber nachdenkt, dass auch der erste Psalm die selig preist, die ,Tag und Nacht vom Gesetze Gottes handeln' [Ps. 1,2]. Ohne Zweifel wirst du keinen Weihrauch noch anderes Räucherwerk stärker gegen den Teufel errichten, als wenn du mit Gottes Geboten und Worten umgehst, davon redest, singst oder denkst. Das ist freilich das rechte Weihwasser und Zeichen, davor er flieht und sich jagen lässt. Nun solltest du doch ja allein um dessen willen solche Stücke gerne lesen, reden, denken und handeln, wenn du sonst keine andere Frucht und Nutzen davon hättest, denn dass du den Teufel und böse Gedanken damit kannst verjagen; denn er kann Gottes Wort nicht hören noch leiden. Und Gottes Wort ist nicht wie ein anderes loses Geschwätz [...], sondern wie S. Paulus Römer 1,16 sagt, ,eine Kraft Gottes', ja freilich eine Kraft Gottes, die dem Teufel das gebrannte Leid antut und uns über die Maßen stärkt, tröstet und hilft." (GK, BSLK 549,21-550,7.) Wir benötigen den Katechismus wie das tägliche Brot, um den „Anfechtungen und Ausspähungen des in tausend Künsten versierten Teufels“ täglich widerstehen zu können (GK, BSLK 550,28-30). Deshalb soll man uns bei Verachtung des Katechismus 
„nicht zu fressen geben, [...] mit Hunden hetzen und mit Lungen auswerfen (= mit Kot bewerfen)", weil mit der Katechismusverachtung und Vernachlässigung wir das Wort Gottes als das tägliche Brot wider den Bösen verschmähen (GK, BSLK 550,23-28). Wer nicht aktuell den Katechismus treibt, sondern inn nur als Früher-Gelerntes in der Vergangenheit lässt, hat nicht nur keinen Ertrag, sondern gerät auf Verderben bringende Abwege: „Wenn du aber die doctrina Catechismi, die du früher gelernt hast, [sc. dort in der Vergangenheit] anstehen lässt und hörest allein, was dir der Schleicher [satanische Irrlehrer] sagt, so ist es mit dir geschehen." (WA 37, 126,22-24.) Christus selbst lehrt uns: Wer nicht auf den Katechismus hört, gerät unter die Herrschaft des Bösen, des Teufels. 48

Fallstricken des Teufels, wie abergläubische, die Gewissen belastende Zeremonien und als solche christliche Freiheit außer Kraft setzen wollende menschliche Satzungen und Knechtungen 49 und falschen Propheten gegenüber 50 kann mittels des Katechismus widerstanden werden. Durch das Katechismustreiben wird den Zeremonien, das sind die „Zunder des Aberglaubens“ der Boden entzogen. Luther sagt in einer Tischrede: „Wenn wir den Katechismus erhalten könnten und die Schulen den Nachkommen aufrichten, so hätten wir richtig gelebt." Zeremonien - die im Papismus reichlich verbreitet waren und sind - „mögen immer vergehen, denn sie sind das Zündpulver, das Ursache-geben zum Aberglauben“. 51

\section{Aneignung des Katechismus}

Luther ermahnt nachdrücklich, Jugendliche und Kinder zu GottFürchtenden und Gott-Liebenden, Gott-Dienenden zu erziehen, denn Eltern und Erziehende haben dazu eindeutiges göttliches Mandat: „Es ist dir [von Gott] ernstlich geboten, dass du sie [= die Kinder] zu Gottes Dienst erziehen sollst. Oder du sollst mit [deinen] Kindern und mit allem ganz entwurzelt sein, auf dass alles

„Sed Christus: Si non nos vis audire Catechismum, tum iterum sub Teufel.“ (WA $37,560,1 f$.) 
verdammt sei, was du an sie verwendest." (WA 30 II, 531,19-22.) Entsprechend legt Luther Wert darauf, den Katechismus so zu vermitteln, dass der konkrete Adressat der Katechismusvermittlung im Auge ist. Das gilt insbesondere auch bei der katechetischen Kindererziehung. Luther begründet die kindgemäße Zuwendung christologisch: „Da Christus Menschen erziehen wollte, musste er Mensch werden. Sollen wir Kinder erziehen, so müssen wir auch Kinder mit innen werden." (WA 19, 78,13-15.) Aus christologischinkarnatorischem Grund hat der den Katechismus bei Kindern Lehrende sich auf Kinder einzustellen. Ja er muss in gewisser Weise Kind werden, d. h. kindgemäße Vermittlung des Katechismus bei Kindern ist theologisch um Christi willen unbedingtes Erfordernis: „Wenn wir Kindern predigen, müssen wir auch mit ihnen lallen." (WA 30 I, 143,9f.)

Der Katechismus darf Jugendlichen und Kindern nicht eingeprügelt werden, denn diese Art von Katechismuserziehung ist nicht produktiv. Sie funktioniert nur solange, wie die Stockstrafe sich vollzieht; d.h. sie gelingt nicht. Fruchtbarer Boden kann so für den Katechismus nicht aufbereitet werden. Es wäre auch Schaden bringend für das Gute im Land. Kindererziehung und damit Katechismusvermittlung kann auf Prügelgrund nicht Wurzeln schlagen. Diese müssen vielmehr unbedingt Erziehung des Herzens sein, in diesem verwurzelt werden. Nicht mit Ruten und Schlägen, sondern mit Guten und Lust kommt es zur Herzensverwurzelung des Katechismus. 52 Wenn der Katechismus nur wörtlich gekannt wird und nicht leidenschaftlich heute im Herzen brennt, wird er keine Zukunft haben. 53

52 „Siehe so möchte man die Jugend [in] kindlicher Weise und spielerisch aufziehen in Gottes Furcht und Ehre, dass das erste und andere Gebot fein im Schwang und steter Übung ginge. Das könnte etwas Gutes wurzeln, aufgehen und Frucht schaffen, dass solche Leute erwüchsen, derer ein ganzes Land genießen und froh werden möchte. Das wäre auch die rechte Weise, Kinder wohl zu erziehen, weil man sie mit Gutem und Lust gewöhnen kann. Denn, was man allein mit Ruten und Schlägen soll zwingen, da wird keine gute Art draus, und wenn man es weit bringt, so bleiben sie doch nicht länger fromm, wie die Rute auf dem Nacken liegt. Aber hier wurzelt es ins Herz, dass man sich mehr für Gott, als für vor den Ruten und Knüttel fürchte. Das sage ich so einfältig für die Jugend, dass es doch einmal eingehe. Denn weil wir Kindern predigen, müssen wir auch mit innen lallen." (GK, BSLK 579,18-38.)

53 "Quanquam scis verbatim catechismum, tamen cor nondum calidum, cras frigidum erit." (WA $34 \mathrm{II}, 336,22 \mathrm{f}$.) 
Mit den Kindern lallend, also Kindes gemäß den Katechismus zu vermitteln, bedeutet auch „spielerisch“ (GK, BSLK 579,19) den Katechismus bei Kindern zu treiben. Luther schlägt exemplarisch ganz konkrete Kinderkatechismusspiele - so ein Glaube-LiebeBeutelspiel - vor: „Solche Frage mag man nehmen aus unserem Betbüchlein, da die drei Stücke (sc. Dekalog, Credo, Vaterunser) kurz ausgelegt sind, oder selbst anders machen, bis dass man die ganze summa des christlichen Verstandes in zwei Stücken als in zwei Säcklein fasse im Herzen, welches sind Glaube und Liebe. Des Glaubens Säcklein habe zwei Beuteleins; in das eine Beutelein stecke das Stück, dass wir glauben, wie wir durch Adams Sünde allzumal verderbt (Röm. 5,12; Ps. 21,7), Sünder und verdammt sind. In das andere stecke das Stücklein, dass wir alle durch Jesus Christus von solchem verderbten, sündhaften (Röm. 5,18f.; Joh. $3,16 \mathrm{ff}$.), verdammten Wesen erlöst sind. Der Liebe Säcklein habe auch zwei Beutelein. In dem einen stecke dies Stück, dass wir jedermann sollen dienen (Röm. 13,8-10) und wohl tun, wie uns Christus getan hat. In den anderen stecke das Stücklein, dass wir allerlei Böses gerne leiden und dulden sollen." (WA 19, 77,11-23.) Luther rät bei der katechetischen Kindererziehung diese spielerischen Erkenntnisspiele produktiv anzuwenden, z. B. so, dass man Groschen und Gulden in die beiden Beutel (Glaube und Liebe) verteilt etc. (WA 19, 77, 24ff.).

Aber natürlich kann der Katechismus nicht nur spielerisch und mit den Kindern lallend vermittelt und angeeignet werden. Es gibt andere Instrumente und Methoden, die zur Anwendung kommen müssen. Allerdings haben alle dazu zu dienen, dass sie im Herzen der Menschen sich verwurzeln. Luther kennt auch das Katechismusverhör als inm notwendiges Mittel. Der Katechismus muss dem Christen lebendig gegenwärtig sein, wenn er dem Glaubenden förderlich sein soll. Darüber, dass das auch tatsächlich der Fall ist, kann und darf nicht gemutmaßt werden. Das muss kontrolliert vergewissert werden. Der Vergewisserung der Gegenwärtigkeit des Katechismus - also, dass Dekalog, Credo und Vaterunser wirklich beim Teilnehmer eines sakramentalen Gottesdienstes aktual gegenwärtig sind $\mathbf{5 4}$ - dient das Katechismusverhör: „Denn Katechismus (sagen die Griechen) heißt eine Lehre, die man fragt und

Im Protokoll über die Kirchenvisitation in Pollersdorf bei Wittenberg (1528) steht: „Unverhört der Beichte der Zehn Gebote, Glaubens und Vaterunsers [die zweite Fassung von 1533 fügt hinzu: und der Worte vom Sakrament] soll niemand das Sakrament des Leibes und Blutes Christi gereicht werden." (Zit. Albrecht, 1915:33.) 
verhört, wie ein Schulmeister lässt die Schüler ihre Lektion aufsagen, ob sie sie können oder nicht. Also soll man vorher [sc. vor dem Sakramentsempfang] die groben Leute verhören und aufsagen lassen, ob sie die Stücke des Katechismus [sc. Glaube, Vaterunser, Zehn Gebote] wissen und sie die dagegen getane Sünde verstehen und hinfort mehr lernen und sich bessern wollen, und sonst nicht zum Sakrament zulassen." (WA 30 III, 567,19-24.)

Gute Lehrer des Katechismus sind nicht häufig zu finden. Auch wird innen menschlicher Ruhm und Ehre kaum zuteil. Allerdings sind sie von größtem Nutzen und die Besten von allen: „Für die besten und nützlichsten Lehrer aber und für ein Muster halte man die, die den Katechismus wohl treiben können, d.h. die das Vaterunser, die Zehn Gebote und den Glauben recht lehren. Das sind seltene Vögel. Denn es ist bei ihnen kein großer Ruhm noch Glanz, aber doch großer Nutzen. Es ist auch die nötigste Predigt, weil darin die ganze Schrift kurz inbegriffen ist, und es gibt kein Evangelium, das solches nicht lehren könnte; wenn man es nur tun wollte und sich des gemeinen armen Mannes annähme, inn zu lehren." (WA 23,18-34.) Sie bläuen dem gemeinen Volk, das wenig vom Dekalog, Credo und Vaterunser kennt, den Katechismus ein; und das ist sehr notwendig. 55 Dieses Einbläuen des Katechismus ist für Luther ein Mittel unerlässlicher Katechismuszucht.

Alle sind im christlichen Gemeinwesen der Katechismuszucht unterworfen: „Das christliche Haus, Kirche und Schule unterwerfen sich der Zucht des Katechismus; die Christen im Amt der weltlichen Obrigkeit leiten und überwachen diese Unterweisung."56 Eltern haben Kinder zu „erziehen mit Zucht, Ehre und Gottesfurcht" (WA $30 \mathrm{I}, 34,34)$. Luther wertet die Zucht als tägliches Brot. In Luthers Erklärung zur 4. Bitte des Vaterunsers („Unser tägliches Brot gib uns heute“) gehört Zucht zum täglichen Brot. „Was heißt denn tägliches Brot? Antwort: Alles, was zur Leibesnahrung und Notdurft gehört, wie Essen, Trinken, Kleider, Schuh, Haus, Hof, Acker, Vieh, Geld, Gut, frommer Gemahl, fromme Kinder, frommes Gesinde, fromme und getreue Oberherren, gutes Regiment, gutes Wetter, Friede, Gesundheit, Zucht (hervorgehoben von U.K.), Ehre, gute Freunde,

55 „Man muss ja dem Pöbel kurze Dinge immer einbläuen wie das Vaterunser, die Zehn Gebote und den Glauben und danach in allen Evangelien und Predigten darauf dringen und treiben. Sie lernen dennoch, leider, wenig genug davon." (WA 23, 486,34-37.) 
getreue Nachbarn und desgleichen." (KK, BSLK 514,1-10.) Zucht darf nicht mit physischer und psychischer Nötigung identifiziert werden. Mit Bezug auf Epheser 6,4 weist Luther auf den Verderben bringenden Zorn bei der Kindererziehung. Dieser verunmöglicht Katechismuszucht und rechtes Katechismustreiben, denn hier ist "Zucht und Vermahnung" nicht Eigentum der zornigen irdischen Väter, sondern solche im Herrn.57 Luther versteht Zucht als vernünftiges, durch Besonnenheit gekennzeichnetes erzieherisches Verhalten: „Das Wörtlein Zucht ... heißt, dass wir auf Deutsch sagen, mäßig, fein, säuberlich, vernünftig fahren an Gebärden“ (WA 30 I, 374 Anm. 4). In diesem Sinne hat der pater familias als Bischof seines Hauses (WA 30 I, 58,8f.) Katechismuszucht durchzuführen.

Wie soll man sich aber verhalten, wenn Kinder sich dem Evangelium gegenüber verschließen? Ist hier mit harter Hand und drastischen Strafen darauf zu dringen, dass sie von ihrer Verweigerung ablassen? Luther lehnt das kategorisch aus theologischen Gründen ab. Man kann und soll in äußeren Dingen Kinder und Jugendliche, die dem Gemeinwohl schaden, erziehen, auch äußerlich strafen und züchtigen, um sie vom Bösen zu bewahren. Aber über die Seele, das Innere eines Menschen, ist nicht mit äußerer Gewalt Änderung zu bringen. Deshalb rät Luther nachdrücklich so zu verfahren: „Wo Kinder das Evangelium nicht annehmen wollten, soll man darum nicht von ihnen lassen noch verstoßen, sondern sie pflegen und versorgen wie die allerbesten Christen, und ihren Glauben Gott befehlen, sofern sie sonst in andern Dingen gehorsam und fromm sind, was das äußerliche Wesen betrifft. Denn äußerlichem bösen Wesen und Werken sollen und können die Eltern wehren und strafen. Dem Unglauben und innerlichen bösen Wesen kann niemand wehren und strafen als Gott allein." (WA 12, 122,31-123,1.)

Allerdings darf die Freiheit des Glaubens nicht dazu führen, störrischer Katechismusverweigerung die Tore zu öffnen. Katechismusverweigerung ist Christusverleugnung. Wer jene tut, empfängt diese. Katechismusverweigung führt zum Ausschluss von den Sakramenten und kann für störrische Kinder und rohe Leute, die das Gemeinwohl gefährden, nun doch auch zu Sanktionen führen. Denjenigen, die den Katechismus „nicht lernen wollen“, sage man, wie sie dadurch "Christum verleugnen und keine Christen sind. Sie 
sollen auch nicht zum Sakrament zugelassen werden, kein Kind zur Taufe heben, auch kein Stück der christlichen Freiheit gebrauchen, sondern schlechterdings dem Papst und seinen Offizialen, dazu dem Teufel selbst überlassen sein. Dazu sollen innen die Eltern und Hausherrn Essen und Trinken versagen und sie anzeigen, dass solche rohe Leute der Fürst aus dem Land jagen wolle etc. Denn, obwohl man zum Glauben zwingen niemand kann noch soll, soll man doch den Haufen dahin halten und treiben, dass sie wissen, was Recht und Unrecht ist bei denen, bei welchen sie wohnen, sich nähren und leben wollen. Denn wer in einer Stadt wohnen will, der soll das Stadtrecht wissen und halten, das er genießen will. Gott gebe, er glaube oder sei im Herzen für sich ein Schalk oder Bube." (KK, BSLK 503,33-504,12.)

Katechismuszucht wehrt der verderblichen Laxheit hinsichtlich des Glaubens, einschließlich der Sakramentszulassung. Die Verweigerung von beiden hat ihre Ursache in falsch verstandener christlicher Freiheit, die in schädlichen Glaubensruin führt: $\mathrm{Da}$ „nun die Tyrannei des Papstes weg ist, so wollen sie nicht mehr zum Sakrament gehen und verachten es. Hier ist aber notwendig zu treiben, doch mit diesem Bescheid: wir sollen niemanden zum Glauben oder zum Sakrament zwingen, auch kein Gesetz noch Zeit, noch Stätte bestimmen, aber also predigen, dass sie sich dasselbe ohne unser Gesetz andringlich fordern und geradezu uns Pfarrer zwingen, das Sakrament zu reichen, welches tut man also, dass man ihnen sagt: Wer das Sakrament nicht sucht noch begehrt zum wenigsten einmal oder viermal im Jahr, da ist zu befürchten, dass er das Sakrament verachte und kein Christ sei, gleichwie der kein Christ ist, der das Evangelium nicht glaubt und hört; denn Christus sprach nicht [1. Kor. 11,24f.]: ,Solches lasst' (...) [sondern]: Solches tut." (KK, BSLK 505,48-506,19.)

Es genügt nicht, „den Text [sc. des Katechismus'] nur gut zu können", sondern der Katechismus ist so zu treiben, dass er von Lehrenden und Lernenden mit „Verstand“ angeeignet wird, damit sie „wissen“, was er tatsächlich bedeutet (KK, BSLK 504,13-15).

Dem Katechismuslernen und vertiefter Aneignung des Katechismus dient auch der lutherische Choral. Zu den fünf Hauptstücken des Katechismus setzte Luther entsprechende Choräle: 1. Dekalog: Dies sind die heiligen Zehn Gebot (AWA 4, 149-153. Evangelisches Gesangbuch [EG] 231), 2. Credo: Wir glauben all an einen Gott (AWA 4, 238-241. EG 183), 3. Paternoster: Vater unser im Himmelreich (AWA 4, 295-298. EG 344) und 4. Taufe: Christ unser Herr zum Jordan kam (AWA 4, 299-301. EG 202) und 
5. Abendmahl. Jesus Christus, unser Heiland, der von uns den Gotteszorn wandt58 (AWA 4, 168-170. EG 215f.) und Der heilig Leib, der ist für uns gegeben (EG 214, Strophe 2). Die musikalische Transkription des Katechismus ist nicht hoch genug zu werten. Sie hat wesentlich nicht nur zur Verinnerlichung, sondern auch zum Wissen des Katechismus im lutherischen Raum und darüber hinaus beigetragen.

Für Luther steht eindeutig fest, wer bewusst den Katechismus ignoriert, ist nicht mehr Christ: „Wer den Katechismus nicht kann, soll nicht ein Christ heißen, nicht zum Sakrament Abendmahl zugelassen werden. Er soll auch nicht Pate werden." (WA 29, 471,22f.) Ein Christ muss mit Notwendigkeit den Katechismus kennen, sonst gehört er nicht zur Zahl der Christen. 59 Ein sicheres Zeichen der Gottes- und Christusverachtung ist die Katechismusnegation. 60 Das trifft auch für denjenigen zu, der doctrina falsa, d.i. Lehre wider die Heilige Schrift, betreibt. Die daraus zu ziehende notwendige Folge, die an diesem zu vollziehen ist, heißt Entfernung aus dem kirchlichen Amt. „Wer aber unrecht lehrt wider die Schrift und Gottes Wort, den entlasse man. Aber ausrotten soll man ihn nicht." (WA 52, 838,23-25.)

\section{Katechismus als doctrina}

Jeder Christ muss den Katechismus treiben. 61 Ja von den Lutheranern sagt man, dass sie „nichts anderes wissen zu lehren als Glauben (fidem) und Katechismus" (WA 25, 184,8f.); und in der Tat schreibt Luther: Der Katechismus ist „nostra doctrina" (WA 54, 453,3-6). Das impliziert, dass ,jeder Christ aus Notwendigkeit den Katechismus kennen (scire) muss" (WA 30 I, 2,4f.). Unter dem Papsttum herrscht doctrina humana. Diese „doctrina humana unterdrückt und lässt ab vom Katechismus" (WA 47, 479,40).

58 Nach dem lateinischen Hymnus Jesus Christus nostra sulus des Johannes von Jenstein (vor 1400) von Luther 1524 verfasst.

59 „Nam quisque Christianus pro necessitate scire debet Catechismus, qui eum ignorat, non est recensendus in numero Christianorum." (WA 30 I, 2,4-7.) jemand, der „von Gott und Christus nichts hält“ (WA 30 I, 57,9f.). 
Nach Calvin haben sich „Bischöfe und die Kirchendiener (ministri ecclesiarum) treu dem Dienste des Wortes (ministerium verbi) zu widmen". Dieser besteht darin, unverfälscht die pura et sincera doctrina (reine und echte Lehre) dem Volk weiterzugeben (tradere), und durch das Beispiel des eigenen Lebens (exemplum vitae) das Wort Gott zu unterweisen (instituere). 62 Auf die rechte, echte reine Lehre kommt es auch bei Luther an, denn falsche Lehre (falsa doctrina) ist Entheiligung und Schändung von Gottes Namen. 63 Für Luther ist jedoch himmelweite Differenz zwischen Lehre und Leben zu konstatieren. Jene hat als doctrina dei (Lehre Gottes) reine Lehre (pura doctrina) zu sein, dieses (unser Leben) ist menschlich fehlbar: „Es ist ein gar großer Unterschied zwischen Lehren und Leben, so wie zwischen Himmel und Erde ein großer Unterschied ist. Das Leben mag wohl unrein, sündig und gebrechlich sein, aber die Lehre muss rein, heilig, lauter und beständig sein. Im Leben mag es wohl fehlen, dass es nicht alles hält, was die Lehre will; aber die Lehre (sagt Christus) darf nicht an einem Tüpfelchen oder Buchstaben fehlen, obwohl das Leben wohl ein ganzes Wort oder eine Zeile in der Lehre auslässt. Ursache ist die: Die Lehre ist Gottes Wort und Gottes Wahrheit selbst; aber das Leben ist unser Mittun. Darum muss die Lehre ganz rein bleiben, und wer am Leben fehlt und gebrechlich ist, da kann Gott wohl Geduld haben und vergeben. Aber die Lehre selbst danach man leben soll, ändern oder aufheben, das kann und will er nicht leiden." (WA 30 III, 343,23-33.) Neben dem großen Unterschied von Lehre und Leben gilt doch auch für Luther der Zusammenhang von beiden. Pura doctrina gibt Hoffnung der Lebensverbesserung: „Wenn die Lehre rein bleibt, so ist Hoffnung, dass auch das Leben leicht gebessert wird (spes est vitae facile corrigendae)“, sagt Luther und illustriert das mit einer Metapher: „Der Sonnenglanz ist rein, wenn er gleich auf Dreck fällt und scheint. Und Gott erhält etwas Heiliges (sanctum) unter uns, wenn wir [...] fallen sollten. Das ist sein Wort, durch das wir alsbald den Irrtum verdammen. Das hält der Herr für groß und hat es lieb."

(WA 13, 688,13-17.) Für Luther gilt jedoch eindeutig aus soteriologischen Gründen die Priorität der pura doctrina vor dem Leben: „Es liegt nun bei weitem nicht so sehr am Leben wie an der Lehre: Wenn das Leben schon nicht so rein ist, kann dennoch die Lehre wohl rein bleiben; mit dem Leben muss man Geduld haben

63 „Econtra falsa doctrina entheiliget nomen dei, sic mala vita schändet seinen Namen." (WA 30 I, 12,31f.) 
[...]. Das Leben wird die Lehre nicht erreichen, solange wir hier leben." Das sähen wir an dem nicht fehlerfreien und zuweilen Narrenhaften und Schwachheit ausmachenden Leben der Apostel (WA 24, 607,3-5.23-30).

Rechte reine doctrina christiana kann vom Menschen nicht selbsteigen konstruiert werden, sondern ist von Gott zu erbitten: „Du bittest also dieses (sc. Geheiligt werde dein Name), damit [...] der Vater durch Christus macht (faxit), damit wir alle unam puram doctrinam (eine rein Lehre) haben und unam sanctam vitam (ein heiliges Leben), damit wir nichts lehren in dem selben Namen, als das, was er selbst vorgeschrieben hat, damit jenes, was wir lehren, das Wort desselben sei." (WA 30 I, 12,15-18.) Rechte sacra doctrina ist göttlich inspiriert. 64 Als „brevis summarium der Heiligen Schrift" ist der Katechismus göttlich inspiriert. Von daher ist er auch die Lehre, die dem Menschen zum Sakrament vorbereitet. 65 Und es gilt: „Wer die Erkenntnis (cognitionem Catechismi) nicht hat, kann nicht Christ genannt werden, nicht zum Sakrament zu gelassen werden." (WA 29, 471,21-23.) Im Katechismus ist „der ganze Inhalt christlicher Lehre“, der für sein Heil notwendig ist, enthalten. In ihm ist „die rechte, wahre, alte, reine göttliche Lehre der heiligen christlichen Kirchen zusammengefasst". Und was dem Katechismus widerspricht, ist Verderben bringende "Neuerung und falsche, irrselige Lehre", vor der wir uns zu hüten haben. 66 Den Katechismus abhorret literis et vocibus tradi." (WA 6, 29,5f.) $30 \mathrm{I}, 109,21$.

„Der Katechismus ist der Laien Bibel, darin der ganze Inhalt christlicher Lehre, die einem jeden Christen zur Seligkeit zu wissen nötig (ist), enthalten (ist). Wie das Hohelied Salominis canticum canticorum, ein Gesang über alle Gesänge genannt wird, also sei decalogus doctrina doctrinarum, eine Lehre über alle Lehre, daraus Gottes Willen erkannt [wird], was Gott von uns fordert und was uns mangelt.

Symbolum, das Bekenntnis des heiligen christlichen Glaubens, est historia historiarum, eine Historie über alle Historien, die allerhöchste historia, darinnen uns die unermesslichen Wunderwerke göttlicher Majestät von Anfang bis in Ewigkeit vorgetragen werden, wie wir und alle Kreatur erschaffen, wie wir durch den Sohn Gottes vermittelst seiner Menschwerdung, Leiden, Sterben und Auferstehung erlöst, wie wir auch durch den Heiligen Geist erneuert, geheiligt und eine neue Kreatur und allesamt zu einem Volk versammelt Vergebung der Sünden haben und ewig selig werden. 
als „Unterweisung oder christlichen Unterricht" haben alle Christen zu kennen. Und sie werden nach und durch die doctrina Catechismi in die Heilige Schrift weiter geführt werden (WA 30 I, 27,28-31).

Der Katechismus ist „kurz begriffen [das], was eine christliche Lehre ist" (WA 30 I, 27,34). Er ist aber nicht irgendeine christliche doctrina, sondern er ist perfectisma doctrina und als solche muss er fortwährend überliefert werden. 67 Auch deswegen ist der Katechismus rechte christliche Lehre, weil er die in inm Konfirmierten in der Rechtfertigung allein aus Glauben befestigt und vor dem Irrtum einer Rechtfertigung auf Grund der Werke bewahrt. 68 Und also „predigen wir sehr sorgfältig den Katechismus, damit sie lernen: nach dem Glauben (post fidem) folgen die rechten guten Werke" (WA 46, 487,4f.). ${ }^{69}$

Christliche Lehre ist eschatologisch dimensioniert. Dem entspricht der Katechismus, denn er ist „ein opus ad vitam aeternam (ein Werk zum ewigen Leben)“ (WA 49, 318,11). Luther verbindet doctrina sincera mit dem Reich Gottes 70: "Wo doctrina sincera ist und Leben, dort wird sein [Gottes] Reich." Dort lebt und regiert Gott selbst mit seiner Gerechtigkeit, seinem Reich. Um dieses Reich wird im Vaterunser gebeten. Dem Reich Gottes stehen gegnerisch das Reich Satans und der Welt gegenüber. Darum bitten wir, dass nicht

Oratio dominica, das Vaterunser, est oratio orationum, ein Gebet über alle Gebet, welches der allerhöchste Meister gelehrt und darinnen alle geistliche und leibliche Not umfasst [hat] und der treffendste Trost in allen Anfechtungen, Trübsalen und in der letzen Stunde.

Sacramenta sunt ceremonia ceremoniarum, die höchsten Zeremonien, welche Gott selbst gestiftet und eingesetzt und uns darinnen seiner Gnade versichert. Deshalb sollen wir ja den Katechismus lieb und wert haben und der Jugend mit Fleiß einbilden, denn darin die rechte, wahre, alte, reine göttliche Lehre der heiligen christlichen Kirchen zusammengefasst, und was dem entgegen ist, für Neuerung und falsche, irrselige Lehre $\mathrm{zu}$ halten, es habe auch so lange gewehrt, wie es wolle, und davor uns hüten sollen." (WA TR 5, 581,30-582,11.)

67 "Catechismus perfectissima est doctrina ideoque tractanda perpetuo." (WA TR 1, 504,24f., [Nr. 1002].)

68 „Pueri et infantes confirmant suo catechismo solam fidem absque operibus iustificare." (WA 30 II, 663,25f.)

$69 \ldots[\ldots]$ omnis nostra doctrina consistat in his duobus: in praedicatione legis, quae docet bona opera, et praedicatione Euangelii, quae docet fidem" (WA 25, $183,41-184,2)$.

Vgl. zum Folgenden (einschließlich Zitate) WA 30 I, 47,26-48,2. 
das Reich des Teufels in uns mit seiner Teufels-, Sünden- und Todeskraft regiere und wir nicht von dessen Lästerungen Gottes und seines Reiches beherrscht werden. Vielmehr bitten wir, dass Tod und Sünde etc. aufgehoben werde bei uns und Gerechtigkeit (mera iustia) Gottes und ewiges Leben Gottes bei uns sei und bleibe.

\section{Der dreieinige Gott setzt den Glauben}

Luther spricht von zwei Arten des Gottesglaubens: 1. dem wissenschaftlichen Glauben und 2. dem Glauben als Vertrauen auf Gott. Beide Gottesglaubensarten gehen von der Existenz Gottes aus. Der erste Glaube ist dadurch gekennzeichnet, dass er generell und vernünftig einen allgemeinen wissenschaftlich evidenten Gottesglauben vertritt. Er sagt: Es ist „wahr, was man von Gott sagt, gleich wie wenn ich glaube, dass wahr sei, was man von Türken, Teufel, Hölle sagt. Dieser Glaube ist mehr eine Wissenschaft oder merckung (= Wahrnehmung) als ein Glaube." (WA 7, 215,2-4.) Die zweite Gottesglaubenart ist gekennzeichnet durch existenzielles Vertrauen auf Gott: „Zum anderen wird an Gott geglaubt, das ist, wenn ich nicht allein glaube, dass wahr sei, was von Gott gesagt wird, sondern setze mein Vertrauen in inn, begebe und erwäge mich mit ihm zu handeln, und glaube ohne allen Zweifel, er wird mir also fromm sein und tun, wie man von inm sagt [...] Solcher Glaube, der es wagt auf Gott, [...], es sei im Leben oder Sterben, der macht allein einen Christenmenschen und erlangt von Gott alles, was er will [...]. Das ist ein lebendiger Glaube, und der wird geboten in dem ersten Gebot, das da sagt: ,Ich bin dein Gott, du sollst keine andern Götter haben'“ Hier gilt nicht: „,Ich glaube [...], von [Gott] dem Vater', sondern ,an Gott den Vater, an Jesus Christus, an den Heiligen Geist'. Und den Glauben soll man niemand geben, denn allein Gott“, dem dreieinigen Gott (WA 7, 215,4-23).

Doctrina christiana hat es mit dem Glauben zu tun, der sein Vertrauen auf Gott setzt. Da dieser Glaube nicht vis et doctrina humana (menschliche Kraft und Lehre) ist, vermag der (glaubende) Mensch auch nicht den Anfang seines Glaubens zu setzen. Das ist vielmehr generell ausgeschlossen. Ich kann den Anfang authentischen Glaubens nicht durch den von mir ermöglichten Beginn konstruieren.71 Frommwerden geschieht nicht durch

71 „Fragst du aber, wie muss man denn anfangen, fromm zu werden, oder was man tun muss, dass Gott in uns anfange? Antwort: Ei, hörst du nicht, dass kein Tun, kein Anfangen in dir ist, fromm zu werden, wie wenig als auch zu nehmen 
Verrichten von eigenen guten Werken: „Wer da fromm werden will, der sage nur nicht: Ich will anfangen und gute Werke tun, dass ich Gnade erlange; sondern so: Ich will warten, ob Gott durch sein Wort mir seine Gnade und Geist geben wolle." (WA 24, 244,31-34.) Luther macht das klassisch im Kleinen Katechismus in der Erklärung zum dritten Glaubensartikel deutlich: „Ich glaube, dass ich nicht aus eigener Vernunft noch Kraft an Jesus Christus, meinen Herrn, glauben oder zu ihm kommen kann, sondern der heilige Geist hat mich durch das Evangelium berufen, mit seinen Gaben erleuchtet, im rechten Glauben geheiligt und erhalten." (KK, BSLK 511,46512,5.) Das Evangelium 72 lehrt uns, dass nicht wir, sondern Gott selbst und kein anderer der Anfänger und Erhalter unseres Glaubens ist. „Darum lerne hier aus dem Evangelium, wie es zugeht, wenn Gott anfängt uns fromm zu machen [...]. Es ist kein anderer Anfang, denn dass dein König zu dir komme und fange in dir an. Das geht also zu: Das Evangelium muss das Allererste sein. Das muss gepredigt und gehört werden. In demselben hörst und lernst du, wie deine Sache nichts sei, und alles Sünde sei, was du tust und anfängst. Sondern dein König [Gott] müsse zuvor dasein und regieren. Siehe, da fängt denn dein Heil an, da lässt du deine Werke fallen und verzagst an dir selbst, weil du hörst und siehst, dass alle deine Dinge Sünde und nicht sind, wie dir das Evangelium sagt, und hebst an, und nimmst auf deinen König, hängst an ihm, rufst seine Gnade an und tröstest dich allein seiner Güte. Dass du aber solches hörst und aufnimmst, ist auch nicht deine Kraft, sondern Gottes Gnade, die das Evangelium in dir fruchtbar macht, dass du ihm glaubst.“ (WA 10 । 2, 29,27-30,7.) Es gilt also: „Dass das Evangelium gepredigt werde und dein König komme, ist auch nicht in deiner Macht oder Verdienst, Gott muss es aus lauter Gnade senden.“ (WA 10 I 2, 30,13f.) „Darum frage nur nicht, wo Anfangen sei fromm zu werden. Es ist kein Anfangen, außer wo dieser König hinkommt und gepredigt wird." (WA 10 । 2, 30,29f.) Glaube ist keine creatura hominis, der als solche „keinen Bestand" hat (WA 17 II, 495,24f.), sondern allein Gottes Werk. Der Katechismus lehrt: Nicht durch eigenes Anfangen, sondern allein durch den vom trinitarischen Gott geschenkten christologischen Anfang kann ich zum lebendigen Gott kommen, wirklich an ihn glauben, inm vertrauen.

und vollenden in dir ist. Gottes allein ist Anfangen, Fördern und Vollenden. Alles was du anfängst, ist Sünde und bleibt Sünde." (WA 10 I 2, 29,5-9.) 
Der von Gott gesetzte Glaube ist also in keiner Weise ein opus hominis (Werk des Menschen). Er hat sein Woher in uns außer uns (extra nos) Menschen. Der Glaube ist wie das Wort nicht aus uns, sondern reine Gabe des Heiligen Geistes (merum donum spiritus sancti). (WA 16, 584, 13-15.) Er ist also „Gotteswerk und Gabe, die der Heilige Geist durch Christus gegeben in uns wirkt" (BSLK 59,17). Der Heilige Geist gibt „niemandem solchen Glauben [...] ohne vorhergehende Predigt oder mündliches Wort oder Evangelium Christi, sondern durch und mit solchem mündlichen Wort wirkt und schafft er den Glauben, wo und in welchem er will. Röm. 10“ (BSLK 59,22-25). Der uns von Gott geschenkte Glaube bringt "gute Früchte" (CA 6, BSLK 60,2f.), denn „in Christus [...] gilt der Glaube, der in der Liebe tätig ist" (Gal. 5,6). Der durch Gottes Rechtfertigung wegen Christus gerechtfertigte Glaube, „schnarcht nicht, noch ist er müßig, sondern wird durch die Liebe wirksam" (WA 40 II, 27,24). Authentischer, durch Gottes Geist von Gott geschenkter Glauben ist „kein Werk, sondern er ist Lehrmeisterin (magistra) und der Leben der Werke (vita operum)" (WA 6, $520,26 f$.).

„Der Glaube blickt unverwandt auf Christus. Er ist auf nichts anderes gerichtet als auf Christus allein, der die Sünde und den Tod überwunden und Gerechtigkeit, Heil und ewiges Leben gebracht hat." (WA 40 I, 545,30-32.) Christlicher Glaube ist Christusglaube. Was aber ist dieser? Christusglaube „ist nicht glauben, dass er [Christus] ein Gott ist oder mit Gott dem Vater in gleicher Gewalt herrscht im Himmel, denn das glauben auch viele andere. Sondern das heißt an Christus glauben, wenn ich glaube, dass er mir ein gnädiger Gott sei, meine Sünde auf sich genommen hat und mich mit Gott dem Vater versöhnt hat, dass meine Sünde seine seien und seine Gerechtigkeit meine" (WA 10 III, 125,23-28; hervorgehoben von U.K.). Der Katechismus schärft mir den Christusglauben als persönlichen mich betreffenden und rettenden ein und nicht als allgemeines religiöses Fürwahrhalten christologischer Topoi.

Der im Katechismus gelehrte Christusglaube, ist aber nicht christusmonistisch mißzuverstehen, obwohl bei Luther die Gefahr christologischer Engführung nicht nur zuweilen nicht zu übersehen ist. Der Christusglaube ist vielmehr elementar trinitarisch vernetzt und kommt nur qua dieser Vernetzung zustande. Trinitarische Glaubenslehre wird im Katechismus geboten. So heißt es in Luthers Großem Katechismus: „,Ich glaube an Gott Vater, der mich geschaffen hat, ich glaube an Gott den Sohn, der mich erlöst hat, ich glaube an den Heiligen Geist, der mich heilig macht.' Ein Gott und 
Glaube, aber drei Personen, darum auch drei Artikel oder Bekenntnisse." (GK, BSLK 647,14-19.) Die drei Artikel des Credos korrelieren den drei Personen. $73 \mathrm{Im}$ 2. Hauptstück (der Glaube) von Luthers Katechismus wird die trinitarische Vernetzung des christlichen Glaubens und die inm entsprechende pura doctrina fundamental theologisch überzeugend ratifiziert: „In dem es uns Wesen und Wirklichkeit des dreieinigen Gottes, wie er in Jesus Christus kraft des Heiligen Geistes als schöpferische Vatergüte zu unserem Heil offenbar ist, nahe bringt, bildet das zweite Hauptstück die innere Sinnmitte des Katechismus, in der zugleich seine christliche Eigenart begründet ist."74 So zielt der Katechismus christologisch im trinitarischen Verbund auf Christus den „punctus mathematicus der Heiligen Schrift" (WA TR 2, 439,25, Nr. 2383), auf das, was Christum treibet. 75 Der Katechismus macht den Christen dadurch elementar aussagefähig hinsichtlich der christlichen Lehre: „Das ganze Evangelium lehrt nichts anderes als den Glauben an Gott und die Liebe zum Nächsten." (WA 8, 15,6f.) Dieser Botschaft dient der Katechismus.

\section{Literatur}

ALBRECHT, O. 1915. Luthers Katechismen. (SVRG 33, Nr. 121/122.) Leipzig. $10 \mathrm{ff}$.

AURIFABER, Tischreden AWA

siehe unten Abkürzungen/Technische Bemerkungen

siehe unten Abkürzungen/Technische Bemerkungen

BEUTEL, A. Hg. 2005. Luther Handbuch. Tübingen: Mohr Siebeck.

BSLK

siehe unten Abkürzungen/Technische Bemerkungen

D'ASSONVILLE, V.E. 2001. Der Begriff "doctrina" bei Johannes Calvin - eine theologische Analyse. Münster/Hamburg/London: LIT Verlag. (Rostocker Theologische Studien, 6.)

73 „Sed vos dividite symbolum in die Hauptstücke nach dem, dass drei Personen sind" (WA 30 I, 86,9f.).

74 Wenz (1996:286f.).

75 „Auch ist das der rechte Prüfstein alle Bücher zu beurteilen (taddelln), wenn man sieht, ob sie Christum treiben oder nicht. Zumal die ganze Schrift Christus zeigt (Röm. 3) und Paulus nichts als Christus wissen will (1. Kor. 2). Was Christus nicht lehrt, das ist nicht apostolisch, wenn's gleich Petrus oder Paulus lehrt. Wiederum, was Christum predigt, das ist apostolisch, wenn's gleich Judas, Hannas, Pilatus oder Herodes täte." (WA DB 7, 384,26-32.) 
FRAAS, H.-J. 1977. Katechismus I/1. (In Müller, G., Hg. Theologische Realenzyklopädie. Berlin/New York: De Gruyter. Bd. 17:710-722.)

GOTTSCHICK, J. 1883. Luther als Katechet. Gießen: Ricker.

HOFFMANN, G. zitiert von Gunther Wenz (1996).

HOLTZ, G. Hrsg. 1962. D. Martin Luthers Großer Katechismus: Vollständige Ausgabe - Sprachlich durchgesehen und den Menschen der Gegenwart nahegebracht von Gottfried Holtz. Berlin: Evangelische Verlagsanstalt.

KAWERAU, G., Hg. 1890. Zwei älteste Katechismen der lutherischen Reformation. Halle/Saale: Niemeyer.

OS siehe unten Abkürzungen/Technische Bemerkungen

OTTO, A. s.a. Vorbemerkung zu den beiden Katechismen. (In WA 30 I, p. 426474.)

PETERS, A. 1990. Kommentar zu Luthers Katechismen Bd. 1: Die Zehn Gebote. Göttingen: Vandenhoeck \& Ruprecht.

SCHILLING, J. 2005. Katechismen. (In Beutel, A. Hg. Luther Handbuch. Tübingen: Mohr Siebeck, S. 305-312.)

SCHWARZWÄLLER, K. 2000. Fülle des Lebens: Luthers Kleiner Katechismus - ein Kommentar. Münster/Hamburg/London: LIT.

SURKAU, H.-W. 1959³. Katechismus. (In Religion in Geschichte und Gegenwart. Tübingen: Mohr Siebeck. [RGG], Bd. 3. S. 1178-1186.)

TRILLING, W. 1992². katecho. (In Balz, W. \& Schneider, G., Hg. Exegetisches Wörterbuch zum Neuen Testament. Stuttgart/Berlin/Köln: Kohlhammer. Bd. 2, 670f.)

VON LOEWENICH, W. 1980. Bilder VI. Reformatorische und nachWA reformatorische Zeit. (In TRE 6, p. 546-557.)

siehe unten Abkürzungen/Technische Bemerkungen

WENZ, G. 1996. Theologie der Bekenntnisschriften der evangelisch-lutherischen Kirche. Bd. 1. Berlin/New York: De Gruyter.

\section{Abkürzungen/Technische Bemerkungen}

OS = Opera Selecta, d.h., Joannis Calvini Opera Selecta. Vol. I-V. 1926-1962. Ediderunt P. Barth, G. (W.) Niesel \& D. Scheuner. Monachii in Aedibus [München]: Chr. Kaiser.

SVRG = Symposion des Vereins für Reformationsgeschichte

TRE = Theologische Realenzyklopädie

Luther wird zitiert nach:

1) Martin Luther, Werke. Kritische Gesamtausgabe, Weimar: Hermann Böhlau, 1883ff. (mit den folgenden Siglen:

WA [Schriften],

WA BR [Briefwechsel],

WA DB [Deutsche Bibel],

WA TR [Tischreden]),

AWA [Archiv zur Weimaraner Ausgabe der Werke Martin Luthers],

[GK = Großer Katechismus]

[KK = Kleiner Katechismus]

2) Die Bekenntnisschriften der evangelisch-lutherischen Kirche, Berlin: Evangelische Verlagsanstalt, 1960 (zitiert: BSLK) 
3) Tischreden oder Colloquia Doct. Mart. Luthers, hg. Johannes Aurifaber, Eisleben 1566 (zitiert: Aurifaber, Tischreden), Faksimiledruck, Leipzig: Edition Leipzig 1981.

RGG = Religion in Geschichte und Gegenwart, Tübingen: J.C.B. Mohr (Paul Siebeck). 1957-1962 ${ }^{3}$, Bd. 1-6.

\section{Key concepts:}

catechetical teaching/catechise

catechism

Luther

Reformation

Kernbegrippe:

kategese

kategismus

Luther

Reformasie 